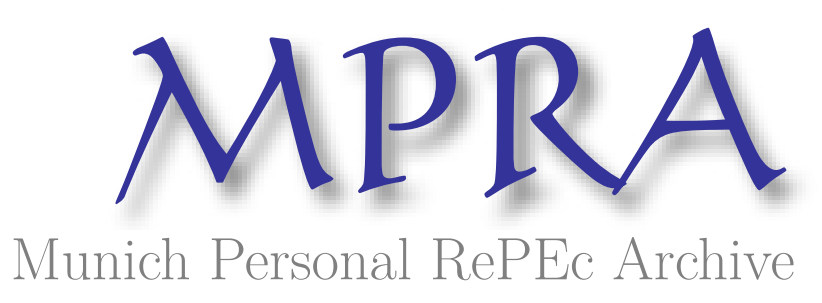

\title{
Internal Labor Markets in Equilibrium
}

Bond, Timothy N.

10 November 2011

Online at https://mpra.ub.uni-muenchen.de/64496/

MPRA Paper No. 64496, posted 23 May 2015 01:28 UTC 


\title{
Internal Labor Markets in Equilibrium*
}

\author{
Timothy N. Bond ${ }^{\dagger}$
}

May 19, 2015

\begin{abstract}
Traditional models of promotion have difficulty explaining why many firms do not favor internal employees for advancement. I develop a new model to explain this phenomenon. My model generates an equilibrium where some, but not all, ex ante identical firms promise to promote internally. These firms employ higher quality entry-level workers, since they hire supervisors exclusively from their lower ranks. The scarcity of high-quality workers limits the use of this strategy. I derive several testable predictions on wage-tenure profile differences across firms with varying promotion practices and confirm these predictions using matched employer-employee data from the United Kingdom.
\end{abstract}

*I would like to thank Marric Buessing, Andrew Ellis, Robert Gibbons, Michael Manove, Daniele Paserman, Claudia Olivetti, Dana Rotz, Laura Salisbury, Johannes Schmieder, Michael Waldman, and, especially, Kevin Lang, and seminar participants at Boston College, Boston University, Carleton University, the Massachusetts Institute of Technology, Miami University, Purdue University, the Royal Economic Association Annual Meetings, the Southern Economic Association Annual Meetings, the University of Adelaide, Università Bocconi, and York University for their helpful comments. I acknowledge the Department of Trade and Industry, the National Institute of Economic and Social Research, the Advisory, Conciliation, and Arbitrary Service, and the Policy Studies Institute as the originators of the 2004 Worker Employee Relations Survey data and the UK Data Archive as the distributor of the data. These organizations bear no responsibility for the analysis of this data herein. All errors are my own.

${ }^{\dagger}$ Department of Economics, Krannert School of Management, Purdue University, 100 S. Grant Street, West Lafayette, IN, 47907; email: tnbond@purdue.edu 


\section{Introduction}

Typical models of promotion focus on the provision of incentives within the firm. In the classic tournament setting of Lazear and Rosen (1981), workers are motivated to exert the optimal effort by a prize that goes to the worker who produces the highest output. However, these models have difficulty explaining the empirical finding that many firms do not favor their own workers for advancement. In my data set, $71 \%$ of workers are employed at an establishment that gives no preference to internal candidates, in spite of the fact that such favoritism is necessary in order to effectively incentivize employees in a tournament setting (Chan, 1996).

I develop a model in which some firms adopt internal promotion to avoid a costly search for higher-level employees on a frictional market. These firms focus their recruitment on workers who appear promising ex ante. Because talented workers are employed at the lower ranks of the firm, foregoing search does not substantially reduce worker quality in its higherlevel positions. It is this synergy which drives the formation of internal labor markets. The fact that talent is scarce limits the viability of this strategy. In equilibrium the number of firms that adopt this policy is limited by the number of workers in the labor pool who appear promising ex ante. This model produces several predictions on how the wages and workforce compositions vary across establishments with differing promotion policies, which I confirm in the empirical section.

Put another way, my model illustrates that hiring selectivity and internal promotion are complementary strategies. ${ }^{1}$ Both recruiting internally and externally for high-ranking positions can be successful and equally profitable provided that it is combined with the proper recruitment strategy at the lower-levels. By closing the model I can determine the equilibrium distribution of these strategies.

The intuition behind the model is quite simple. Imagine a world where talent is both scarce and valuable. Because firms can extract rents from workers, they would like to hire

\footnotetext{
${ }^{1}$ For a comprehensive review of the literature on complementary firm practices, see Brynjolfsson and Milgrom (2013).
} 
the most talented employees and place them in their most productive positions. However, due to the scarcity of talent, some firms will be forced to fill their best positions with lower quality workers. By "locking in" promising young workers and foregoing external search, the firm can increase the likelihood of having high-quality workers at upper-level positions without the costs of external recruitment. ${ }^{2}$ Of course, many firms would like to adopt this strategy and competition will bid up the wages for promising young workers. Given this, some firms choose to wait and attempt to hire workers who, although initially less promising, turn out to be high quality.

I model an overlapping generations economy with two types of workers who differ in their ability to be supervisors. ${ }^{3}$ Workers' true types are unknown, however they possess a publicly observable signal that is correlated with their qualification for supervisory tasks. Firms are ex-ante identical and employ workers in entry-level and supervisory positions. A supervisor is required in order for entry-level workers to produce. "Qualified" supervisors provide extra production for the firm. ${ }^{4}$ Information is incomplete, so firms can extract rents by identifying qualified supervisors. The firm employs two young workers at the entry-level job and must decide whether to promote internal workers (whose ability they will learn) or spend resources to attempt to identify a qualified worker at an outside firm. ${ }^{5}$ The firms report this promotion policy as part of the entry-level contract, and may only offer contracts which self-enforce. In equilibrium firms that promise to promote internally always hire more entry-level workers with high signals. Labor market competition for these workers causes their wages to be bid above their marginal entry-level product. As a necessary and scarce input for the promotion strategy, workers extract the strategy's rents.

Consequently, entry-level workers at internally-focused firms initially earn higher wages

\footnotetext{
${ }^{2}$ This intuition is similar to that of $\mathrm{Li}$ and Rosen (1998), though their model deals with risk aversion in incomplete markets.

${ }^{3}$ As I abstract from incentive provision and focus on the match of workers to jobs, my model is most closely related to the job assignment models of Gibbons and Waldman (1999, 2006). While these models typically consider a single firm in a vacuum, I model many firms which differ in their promotion policy and have equilibrium turnover. For another job assignment model with equilibrium turnover, see Ghosh (2007).

${ }^{4}$ Equivalently, qualified supervisors could make the entry-level workers more productive.

${ }^{5}$ Fixed firm hierarchies and slot constraints for higher level jobs are common assumptions in the tournament literature. See, for example, Waldman (2003), Waldman (2011), and DeVaro and Waldman (2012).
} 
than those at firms which search externally. This difference is short lived; because talent is scarce, the best workers eventually move to supervisory jobs either inside or outside their original firm. The most senior employees at entry-level jobs earn identical wages, regardless of their firm's promotion strategy. Because their window for promotion has ended and they were revealed to be unqualified for supervisory tasks, they provide no value to the firm above their entry-level task production. Therefore, in a cross-section of entry-level workers, we should observe a lower return to tenure at internally-focused firms than at externallyfocused firms. These predictions are confirmed using a matched employer-employee data set from the United Kingdom.

While there is a vast literature on promotions and internal labor markets, there has been little theoretical or empirical work on how promotion policies differ across firms. ${ }^{6}$ Tsoulouhas, Knoeber, and Agrawal (2007) show that firms should set rules that favor internal candidates unless outside candidates are of significantly higher innate ability. ${ }^{7}$ BayoMoriones and Ortin-Angel (2005) find, among Spanish industrial plants, that establishments that are likely to rely on specific capital and that face higher information asymmetries are more likely to promote internally. They find little evidence that promotions are used more frequently in establishments where providing individual incentives appears more important. DeVaro and Morita (2013) model how exogenous firm productivity differences can drive various aspects of organizational structure. In their theoretical model, firms that receive exogenously high value from managers create a more bottom-heavy organizational structure. Thus, the best managerial candidate is likely to be internal due to the larger pool of internal workers. They find empirical support for their theory using establishment characteristics obtained from a questionnaire of managers which is included in my data. ${ }^{8}$

My approach differs in that I do not rely on any exogenous firm characteristics to drive differences in firm practices. Many firm characteristics are actually choices made by the

\footnotetext{
${ }^{6}$ For recent surveys of the promotion literature, see Lazear and Oyer (2013) and Waldman (2007)

${ }^{7}$ See also Kräkel and Schöttner (2012) for a discussion of the conflict between selection and incentives presented by external hiring when workers are heterogeneous

${ }^{8}$ Consistent with this, Martins and Lima (2006) present evidence that firms who have more external hires among their top-management are less productive.
} 
firm simultaneously with promotion policy, or are outcomes of the set of human resource polices the firm chooses to adopt. For example, in my model firms that choose to promote internally will have higher productivity when measured on an output per worker basis because they also choose to recruit higher quality workers. While previous literature has suggested that homogenous firm models may not be able explain differences in internal labor market practices, my model shows that heterogeneity is not always necessary. ${ }^{9}$ All firm heterogeneity in my model is endogenous and generated by two exogenous factors, the distribution of worker quality in the labor force and a search cost common to all firms. Consequently, my testable predictions are on equilibrium wage correlations rather than firm characteristics.

More generally, this article contributes to a growing literature on the impact of external market forces on internal labor markets. Waldman (1984) first considered how the act of being promoted can be a signal of worker ability when information is incomplete. Zábojník and Bernhardt (2001) incorporated this framework into a "market-based" tournament. In this setting, promotion triggers higher outside offers due to changes in market beliefs, and thus the "prize" is endogenously determined. ${ }^{10}$ Chan (1996) considers how the option to hire externally impacts the ability to provide incentives in a promotion tournament. He shows that allowing firms to hire from outside causes the number of players in a promotion tournament to expand dramatically, lowering the incentives of the internal employees. The solution is to use lower requirements when evaluating, and thus give preference to, the internal employees for promotion. Chan (2006) finds empirical support for this model using personnel records from a U.S. financial company. Waldman (2003) analyzes the commitment problem where the ex post optimal hiring rule over-hires outsiders, thus providing inefficient incentives relative to the ex ante optimal rule. Chen (2005) models the decision to recruit externally to prevent a collusive shirking equilibria.

The rest of the paper is outlined as follows. In Section 2, I formally derive my model of promotion and internal labor market creation. I characterize equilibria in which promotion

\footnotetext{
${ }^{9}$ See, for example, the discussion of hiring practices in Oyer and Schaefer (2011).

${ }^{10}$ For more recent work, see Ghosh and Waldman (2009), Zábojník (2012), DeVaro and Waldman (2012), and Waldman (2013).
} 
practices are heterogeneous, and derive testable predictions from the set of properties these equilibria share. Section 3 describes the data. In Section 4, I test the predictions of my model and discuss alternative theories. Section 5 concludes.

\section{A Model of Endogenous Promotion Practices}

\subsection{Primitives}

I use a simple overlapping generations framework. A continuum of heterogeneous workers is born each period. Workers live two periods (young, then old) and have an unknown (to both the worker and the market) type. The type takes two forms and determines whether the worker is qualified to perform supervisory tasks. Conditional on their type and task, workers are equally productive across all firms. While individual workers' types are initially unknown, the market and worker observe a signal of their quality. A worker with a highsignal $(\mathrm{H})$ has probability $p_{H}<1$ of being qualified for supervisory tasks, while a worker with a low signal has probability $p_{L}<p_{H}$ of having that qualification. A fraction $h<\frac{1}{2}$ of the workers have high signals and this fraction is known ex ante to all firms and workers. All cohorts are identical. During the second period of their life span, workers and their employers learn their true type. This information is private from non-incumbent firms.

Firms are infinitely lived and ex ante identical. They consist of two tasks: entry-level and supervisory. Old workers produce $\theta$ at the entry-level task. Young workers require supervision; they produce $\theta$ at the entry-level task if the firm employs a supervisor and 0 otherwise. Only old workers may be employed at the supervisory position. A supervisor fosters production by young workers and also produces, himself. A qualified supervisor produces $(\lambda+1) \theta, \lambda>0$, while an unqualified supervisor produces $\theta .{ }^{11}$ Supervisors may not monitor more than two young workers, and firms are not permitted to employ more than 1 supervisor.

The set of potential entrants is large and of Lebesgue measure greater than 1, but in

\footnotetext{
${ }^{11} \lambda \theta$ thus represents the surplus from employing a qualified worker at a supervisor position.
} 
order to enter they must purchase a factory. ${ }^{12}$ A continuum of identical factories are born each period and fully depreciate at the end of the period. I normalize the set of factories to be of measure 1. Factories cost $r$ which is endogenously determined by the market. The set of workers born each period is of measure $N$. I will restrict attention to the case where $N<2$ but $N \approx 2$. This is to avoid an indeterminacy of wages when labor supply and demand are inelastic and exactly equal. ${ }^{13}$

Firms offer a menu of signal- and co-worker signal-conditional contracts to attract young workers to entry-level positions. ${ }^{14}$ These contracts specify an entry-level wage and policy for hiring its supervisor in the next period. The policy may take two forms:

1. "Promotion Promise" - The firm will fill its supervisory position with its most qualified worker who was employed at an entry-level position in the previous period.

2. "No Promise" - The firm will attempt to hire a qualified external candidate for its supervisory position when its internal candidates are not qualified. ${ }^{15}$

While there is no enforcement mechanism, in equilibrium firms which promise to promote internally must keep their promise. I will model this promise as complete - promotionpromise firms never hire from outside - but this is not necessary for my results. All that is required is that the promise firms hire internally at higher rates conditional on internal candidate quality. I will discuss this point in more depth in section 2.4.2.

Young workers observe all offered contracts and accept the contract which maximizes their expected lifetime utility. The firm's type is thus determined by which of its entry-level contracts are accepted by young workers. I will refer to firms who have a contract accepted

\footnotetext{
${ }^{12}$ The inclusion of factories is simply a device to allow a free-entry equilibrium with zero profits. It can be viewed as analogous to an endogenous sunk cost of capital acquisition for vacancy creation in a search model context. I could, alternatively, fix the number of firms and allow them to earn profits without altering the results.

${ }^{13}$ I could alternatively set $N>2$. This would lower the wages of at least some workers to their outside option, but not fundamentally alter the characteristics of equilibrium.

${ }^{14}$ Note that a contract being co-worker conditional is not important in the baseline model. It would instead arise in the extension discussed in section 2.4.3.

${ }^{15}$ While I omit the option for a firm to promise to hire supervisors only externally, this strategy is always dominated by the no promise contract.
} 
that includes a promotion promise as a promotion-promise firm. Those whose contracts do not include this will be no-promise firms. ${ }^{16}$

Firms do not observe the type of old workers outside the firm. ${ }^{17}$ They may pay a fixed "search cost" $m$ which provides them with limited information on external candidates. This cost is paid before the quality of their workers is revealed. Firms which have entered the search market and do not have a qualified internal candidate may learn about a qualified non-promoted external candidate. For simplicity, each worker is discovered by at most one firm. ${ }^{18}$ If there are more qualified supervisors available than firms searching, each firm discovers a qualified supervisor with probability 1 . If not, the probability that a firm learns of a qualified external candidate is

$$
\phi=\frac{s^{q}}{s^{n q}}
$$

where $s^{q}$ is the measure of the set of workers who are qualified and were not promoted internally and $s^{n q}$ is the measure of the set of firms who did not find a qualified internal candidate and are searching on the market. Firms which do not discover a qualified external candidate may choose to either hire an external worker with unknown type or promote an unqualified internal candidate. When indifferent between these two options, firms always choose the latter.

The timing of the search cost is important. If firms only pay the cost when their internal candidates are unqualified, external hiring becomes a dominant strategy. The timing assumption is reasonable if it is difficult for a firm to adjust its resources due to short-run fluctuations in the number of internal vacancies. If the search cost represents, for example,

\footnotetext{
${ }^{16}$ An alternative and potentially interesting way to view the model is that there are instead a large number of entrepreneurs with exogenous preferences for worker type and promotion policy, who only offer a single contract to workers who fulfill their signal-type requirements. Then the market determines the equilibrium distribution of entrepreneur preferences that exist in the market. This model is equivalent to the one I describe.

${ }^{17}$ To simplify the analysis, I additionally assume that firms do not observe the initial market signal or the signal of the worker's co-worker. Giving firms this information would allow them to form different beliefs about external workers. However, as I will show in the next subsection, in equilibrium firms never hire external workers of which they do not have perfect information about their type, so relaxing this assumption would have no effect on my model.

${ }^{18}$ Relaxing this assumption would allow for some competition for supervisors and thus effect some supervisor wages, but would not alter the main theoretical results.
} 
that a firm which frequently hires externally requires a larger number of human resource professionals, it would be difficult for the firm to lay-off this staff in months in which internal candidates are qualified and re-hire and re-train them in months where they are not.

Because of information asymmetries, there is a surplus when qualified supervisors are employed by firms which know they are qualified. ${ }^{19}$ These wages are thus determined by Nash bargaining. If bargaining breaks down, the firm either promotes an unqualified internal candidate or makes a competitive offer to an external worker of unknown type, while the worker may gain employment at a firm which does not know her type.

Firms simultaneously offer simple wage contracts to remaining old workers to be employed in unsupervised entry-level positions. Old workers remain with their incumbent firm if they are indifferent between multiple offers. ${ }^{20}$

The timing of a period in the model is as follows. First, the market for factories opens. Once that market has cleared, firms must decide whether to enter the search market for supervisors at cost $m$. After this decision, firms learn the quality of their previous period entry-level workers. Firms promote a qualified entry-level worker if one exists. The search market for supervisors then takes place, and random firms who entered the market without a qualified internal candidate learn about a qualified external candidate. Firms Nash-bargain for wages with internally promoted and informed external hires. Firms who remain with a supervisory vacancy fill them by making competitive wage offers to external workers of unknown type or promoting unqualified internal workers. After this, the market for entrylevel workers (young and old) opens and market entry-level wages are determined. Finally, production takes place, cohorts age, and the next period begins.

\subsection{Equilibrium}

To be more precise, I will define equilibrium in the following manner:

\footnotetext{
${ }^{19} \mathrm{I}$ assume that firms do not observe which workers were promoted. This is important, as the promotion decision could provide information to the market, which could in turn raise the wages of qualified supervisors. There is an extensive literature studying promotions as signals. See, for example, Waldman (1984), Zábojník and Bernhardt (2001) and DeVaro and Waldman (2012). While analyzing the organization of promotion practices when promotions act as signals would be interesting, it is beyond the scope of this paper.

${ }^{20}$ One could view this as workers having an $\varepsilon$-sized moving cost.
} 
Definition 1. Equilibrium is a set of period-specific contract outcomes $\Delta$ and a vector of period-specific factory costs $r$ such that

1. Participation: The set of contracts in $\Delta$ that generate negative expected profits for firms or negative expected utility for workers is of measure 0

2. Contract Optimality: There does not exist a contract outside of $\Delta$ that would increase both the expected lifetime profits of a positive-measure set of firms and the expected lifetime utility of a positive-measure set of workers

3. Self-Enforcing Contracts: The set of contracts in $\Delta$ that include a promotion promise and have ex ante positive probability of hiring externally is of measure 0 , and the set of contracts in $\Delta$ that do not include a promotion promise and have ex ante nonpositive probability of hiring externally is of measure 0

4. Bayesian Beliefs: All beliefs are formed by Bayes' Rule and are correct in equilibrium

5. Factory Market Clearing: The excess supply and excess demand for factories is nonpositive in all periods, conditional on $\Delta$

While the equilibrium definition is fairly standard, I emphasize condition (3). All firms that promise to promote internally will promote internally in equilibrium. No firm will ever find it optimal to, for example, break its promise and either enter the external search market or hire an external supervisor of unknown type. Likewise a firm cannot state they will look externally, but then always hire internally.

Definition 2. A steady state equilibrium is an equilibrium in which the set of firms whose accepted contracts vary over time is of measure zero

As is standard with these types of dynamic models, I will restrict attention to steady state equilibria for simplicity. This allows me to focus on whether my equilibrium conditions hold in just one period of the model. 
Definition 3. A trivial equilibrium is an equilibrium in which, in some period, the set of promotion-promise firms or the set of no-promise firms is of measure zero.

Trivial equilibria may exist in theory, but they do not exist in the data. I observe heterogeneity in promotion practices across all industries and occupation groups, so I will not consider any equilibria which cannot replicate this fact.

Definition 4. A talent-scarce equilibrium is an equilibrium in which the set of qualified old workers who are employed at entry-level positions is of measure zero.

Put another way, in a talent scarce equilibrium, not all firms that hire externally will be able to find a qualified supervisor. Talent is scarce so long as there are more firms searching the external search market than there are firms who employed two qualified entry-level employees in the previous period.

I now introduce the main results.

Lemma 5. In all equilibria, old entry-level workers and old workers of an unknown type hired for supervisory positions earn $\theta .^{21}$

Old worker types are not public information; they are viewed by the market as identical. Since all workers produce $\theta$ at entry-level positions regardless of type, incumbent firms who are informed about a worker's type are not willing to offer them a wage higher than $\theta$ for an entry-level position. Thus these workers must earn $\theta$. It then follows that, since the workers are identical to the market and must have identical wages, and there are more old workers than positions for supervisors, that any external worker hired for a supervisor with an unknown type (i.e not through the costly search market) will also be paid $\theta$. Note that since workers always break ties in wage at the same position in favor of the incumbent, all old workers who do not obtain supervisory positions remain employed at their original firms as entry-level workers. These workers do not require supervision at entry-level tasks, so firms do not face a trade-off between old and young workers.

Proposition 6 then follows.

\footnotetext{
${ }^{21}$ Proofs of this result and all others may be found in the appendix.
} 
Proposition 6. All non-trivial equilibria are talent-scarce.

Promotion-promise contracts can only be self-enforcing under talent scarcity. If the equilibrium is not talent scarce, then there are qualified supervisors who are available after the supervisor search market concludes. While firms may not know which workers are qualified, in expectation they are more likely to be qualified than internal candidates who are known to be unqualified. Thus at least some promotion-promise firms would choose to break their promise and hire an external candidate.

Proposition 6 tells us that all old workers who are not employed as supervisors after the search market concludes are unqualified. Since firms promote internally when they are indifferent between external and internal candidates, this means that external candidates will only be hired through the search market. This also pins down the firm's threat point for bargaining - hiring a supervisor at wage $\theta$ who is known to be unqualified with certainty.

Proposition 7. In all non-trivial equilibria, all no-promise firms enter the search market

This result follows directly from talent scarcity. If a firm does not enter the search market, since all external workers that are not supervisors after the search market are unqualified with certainty, it will always promote an internal worker. Thus a no-promise firm that does not pay $m$ and search would violate Self-Enforcing Contracts.

Proposition 8. In any non-trivial equilibrium, the average number of young high-signal workers employed by promotion-promise firms is strictly higher than the average number of high-signal workers employed by no-promise firms.

Proposition 8 expresses the main theoretical result of this paper. Any equilibrium which contains heterogeneous promotion practices will necessarily involve the sorting of high-signal workers into entry-level positions at firms who exclusively promote internally.

In equilibrium, each firm hires two young entry-level workers. ${ }^{22}$ The firm's decision is which signal-type those workers should be and whether to also promise to promote internally.

\footnotetext{
${ }^{22}$ While firms have the incentive to hire young entry-level workers they cannot supervise to learn about their type, because each additional entry-level worker has a decreasingly positive impact on the probability of finding a qualified supervisor internally, no firm would ever be willing to pay the market wage for a third worker.
} 
In order for a promotion promise to be self-enforcing, a firm must find it optimal to not enter the search market. ${ }^{23}$ This will only occur when the a firm has employed relatively ex ante high quality workers. Thus, in any equilibrium we will have sorting of signal-quality by promotion policy. Firms which employ relatively more high-signal workers will offer promotion promises, and those which employ relatively more low-signal workers will make no promises and search. Note that all firms must earn zero profits in equilibrium and thus be indifferent among all the different hiring and promotion strategies implemented. Since promotion-promise firms do not pay the search cost, this cost saving will be offset in equilibrium by high-signal workers earning higher wages. ${ }^{24}$

Definition 9. A full-sorting equilibrium is an equilibrium in which the set of young highsignal workers on no-promise contracts and the set of young low-signal workers on promotionpromise contracts is of measure 0 .

The full-sorting equilibrium illustrates the implications of the model most clearly. ${ }^{25}$ In this case, the number of high-signal workers perfectly determine the number of firms that promise to promote internally. In other words, the internal promotion strategy is strictly limited by the talent pool of the labor force. In such an equilibrium it is likely that firms that have promised to promote internally actually obtain more qualified supervisors than those that do not limit their search. However, there are simply no more of the high-signal workers necessary to adopt this strategy. Subsequently, the wages of those high-signal workers are bid up so as to eliminate the profits from the better quality supervisor. At equilibrium wages, then, firms are indifferent between the adoption of these two competing strategies.

\footnotetext{
${ }^{23}$ In principle a firm could enter the search market and keep their promise by refusing to hire any workers they discover. It should be obvious, given that search is costly, that no firm would ever choose to do so.

${ }^{24}$ This cost saving may also be offset by promotion-promise firms having lower ex post quality supervisors, but as I discuss below this is not always the case. Regardless, the difference in the profitability of these two strategies will load on to the wage of high-signal workers, who are the scarce resource required to implement a promotion promise.

${ }^{25}$ The reason that not all equilibria are full-sorting is primarily because of diminishing returns. The second high-signal entry-level worker raises the probability of employing a qualified supervisor by the less than the first. Since these workers are identical they must be paid identical wages, thus there can be cases where the value of a second high-signal worker to a promotion-promise firm is equal to or less than that of one high-signal worker on a no-promise contract.
} 
Proposition 10. For some set of parameters $p_{H}, p_{L}, \theta, m, h$ there exists a steady-state, non-trivial, full-sorting equilibrium. ${ }^{26}$

Corollary 11. For some set of parameters $p_{H}, p_{L}, \theta, m, h$ there exists a steady-state, non-trivial equilibrium.

I note that when a non-trivial equilibrium exists, it may not be the unique equilibrium or even the unique non-trivial equilibrium for that set of parameters. All non-trivial equilibria, however, share the same properties as discussed in the previous propositions, and thus these will be the core of the predictions I test in the empirical section. I will also briefly discuss some additional implications of the full-sorting equilibrium.

The interplay between several parameters determine whether a non-trivial equilibrium exists, but the search cost is most salient. ${ }^{27}$ When the search cost is very low, only trivial equilibria with no promises exist. Since the option to search externally always yields a weakly better supervisor, if $m$ is zero there is no reason to focus internally. As search becomes costly, firms will promise to promote internally when they hire exclusively high-signal entrylevel workers. Hiring the highest ex ante quality workers minimizes the opportunity cost of forgoing search. As the search cost continues to increase, firms promise to promote internally even when hiring low-signal workers. At some point so many firms are hiring internally that talent is no longer scarce; there are less vacancies at firms that search than there are qualified workers in the market. At that point, we move again into a trivial equilibrium where firms do not promise promotion, bypass the search market, and hire random old workers of uncertain type from the market.

\footnotetext{
${ }^{26}$ Although I prove this in the appendix by showing one possible combination of parameters, there are infinitely many others that would yield such an equilibrium.

${ }^{27}$ It is not feasible given the data to test whether the conditions which generate non-trivial equilibria hold in the data, but it is unnecessary. I can observe from the data that each industry's labor market is in a non-trivial equilibrium, and none of my main predictions depend on these parameters.
} 


\subsection{Predictions}

\subsubsection{Entry-Level Wages and Return to Tenure}

As recruitment and selection are at the forefront of the model, it is not surprising that in these elements promotion practices have the starkest effect.

Proposition 12. In any steady-state non-trivial equilibrium, the average wage of young entry-level workers is higher at promotion-promise firms than no-promise firms

This prediction is due to the equilibrium sorting we see from Proposition 8. As discussed before, high-signal workers will always be relatively more valuable to firms that promise to promote than those who do not. Thus for any given wage, firms that have promised to promote internally will hire more high-signal workers. In equilibrium, the percentage of high-signal workers employed at the average firm that promises to promote is always higher than for the firm that does not. Since high-signal workers provides a higher probability of uncovering a qualified supervisor, which generates profits for a firm, they will always earn higher wages than low-signal workers. Thus the average wage promotion-promise firms pay to their entry-level employees will always be higher.

Note that in the full-sorting equilibrium we can be even more specific. Since this wage difference will just represent the absolute difference between the high- and low-signal wage, and all firms earn zero profits in equilibrium, the observed wage difference is simply the extra value from the promise strategy. This represents that promotion-promise firms do not have to pay the search cost, but also that they may be able to recruit better qualified supervisors in equilibrium.

However, regardless of the equilibrium, this wage difference does not hold for old entrylevel workers

Proposition 13. In any steady-state non-trivial equilibrium, the average wage of old entrylevel workers is identical across firm promotion policies

Young workers are paid above their product at the entry-level task because of the added 
value they bring to the firm as potential future supervisors. This value varies depending on the worker's signal and the firm's promotion policy. However, for old workers, since their type has been revealed and they die the next period, they provide no future benefits to the firm. Since all workers are equally productive at the entry-level task, they earn just that marginal product regardless of their employer. ${ }^{28}$

From these two propositions we can derive three predictions to take to the data:

1. In a cross-section of entry-level workers, we should observe higher wages being paid to the most recent hires at firms that favor internal promotion.

2. In a cross-section of entry-level workers, we should observe a lower return to tenure among workers employed at firms that favor internal promotion.

3. In a cross-section of entry-level workers, we should observe no wage differences associated with a firm's promotion policy among the most senior workers.

Predictions 1 and 3 follow directly from the previous two propositions. The second is implicit - the return to tenure in the model is just the observed difference between old and young workers, given that there is no turnover of workers from entry-level to entry-level. Since the wages of workers at promotion-promise firms start higher, their observed return to tenure must be lower than those at no-promise firms. Note here that I limit the analysis to a cross-section of entry-level workers. The return to tenure for all workers is ambiguous as it depends on the size of the surplus from having a qualified supervisor.

I emphasize that the model does not create a prediction of causality between promotion and hiring selectivity. My model does not differentiate between whether firms implement promotion promises because they hire ex ante high quality workers, or whether they hire ex ante high quality workers because they intend to promise promotion. The practices are determined jointly as neither would be optimal without the other. The predictions are the expected wage patterns as an outcome of implementing these two complementary strategies.

\footnotetext{
${ }^{28}$ Note that the model also predicts that entry-level wages at all employers will decline absolutely with tenure which is clearly not true in the data. This is not uncommon in models of promotion (e.g. Ghosh and Waldman, 2010), and the explanation for this necessarily comes from outside the model.
} 


\subsubsection{Other Predictions}

My model also delivers several predictions which are difficult to test in the data. The existence of multiple equilibria impairs definite predictions on the fraction of any industry which makes a promotion promise. However, in the full-sorting equilibrium the number of high-signal workers perfectly determines the distribution of promotion practices. The breakdown of promotion practices by industry is something that I can analyze in the data.

My model unambiguously predicts that there will be higher turnover from entry-level positions at firms that promise to promote than those that do not. Since no-promise firms promote internally when they cannot find a qualified applicant on the market, the only turnover is of qualified workers from entry-level positions to supervisory positions. Promotion-promise firms hire more high-signal workers to their entry-level positions, so they will have more qualified workers available to the market. Unfortunately, data on turnover at the job-level is unavailable.

\subsection{Model Robustness}

\subsubsection{Heterogeneous Entry-Level Productivity}

In my baseline model, a worker's true-type did not impact their productivity at the entrylevel. Relaxing this assumption has no impact on my results. When qualified workers are more productive at the entry-level task, it raises their wage by the amount of the productivity increase. Since promotion-promise firms employ more high-signal workers, and high-signal workers will now be more productive in expectation, the entry-level wage gap between promotion-promise and no-promise firms for young workers increases. As talent is always scarce in non-trivial equilibria, all old qualified workers are employed in supervisory positions. Thus, the workers with the initial productivity advantage held by entry-level workers at promotion-promise firms vanishes; the most productive workers have left the position. As a result, both Proposition 8 and all three of the predictions in section 2.3.1 hold. 


\subsubsection{Weak-Promise Contracts}

In my baseline model, promotion-promise firms only fill their supervisor position internally. However, very few firms have rigid rules against external hiring. Instead, firms may give preference to internal candidates, but still reserve the right to occasionally hire externally. In fact, in my empirical section, the firms I equate to "promotion-promise" primarily report that they simply give preference to internal candidates.

In an environment where firms only promise to give extra consideration to internal candidates, my results still hold. Suppose that all firms have a chance to learn about qualified external candidates, but firms may pay a search cost $m$ to increase this probability. Promotion-promises in this environment are then self-enforcing contracts to not pay the search cost. Even though firms which favor internal promotion have the opportunity to hire externally, because they have chosen a policy which gives them less opportunity to do so, they still value high-signal workers more. Likewise, firms which hire ex ante high-quality workers are more willing to forgo the cost of increasing their search success rate. Favoring internal promotion and hiring high-quality entry level workers remain complementary strategies.

\subsubsection{Commitment and Legally-Enforceable Contracts}

In my baseline model, firms are not able to commit to multi-period contracts. Therefore, I consider only equilibria in which the firm finds it optimal at every stage to follow through with its initial promise. Whether and how a firm commits to policies is a central question in personnel economics, one which is beyond the scope of this paper. ${ }^{29}$ That being said, it is straightforward to show that allowing firms to commit to promotion policies at the hiring stage has only a minor impact on my main results.

Commitment to internal promotion primarily effects the model through a firm's threat point in supervisor wage negotiations. Without commitment, a firm which fails to negotiate

\footnotetext{
${ }^{29}$ For a detailed analysis of the commitment problem in promotion decisions, see Waldman (2003). Among the ways Waldman discusses that a firm can commit to a policy are rigid and bureaucratic human resource departments, and long-term reputation effects.
} 
a contract with its best internal employee may hire from outside the firm. With commitment, the firm will be required to leave the position vacant. Qualified internal candidates will thus earn higher supervisory wages at firms which commit to internal promotion than uncommitted firms, and unqualified internal candidates will be able to earn a wage above their productivity at entry-level tasks.

In equilibrium, provided there is a reasonable distribution of the bargaining power, we will still have the sorting of high-signal workers into promotion-promise jobs. ${ }^{30}$ A firm will only be willing to commit if it has a reasonable expectation of finding a qualified internal candidate, and this can only be achieved with high-signal workers. Conditional on a worker's signal, however, committed firms will be able to pay lower entry-level wages than uncommitted firms, since these firms' worse bargaining position leads to higher potential future supervisor wages. Whether the wage predictions of section 2.3.1 hold will depend on whether the sorting effect or the pay effect dominates, and thus depends on the parameters of the model.

Perhaps the most important change is the existence of non-trivial, non-talent scarce equilibria. Since firms can commit, they can enact a promotion policy even when there will be qualified old workers at other firms in entry-level positions. These equilibria are all $e x$ post inefficient. Internally promoted unqualified supervisors should be replaced by qualified workers at other firms, but the commitment precludes this. Nonetheless, these inefficient equilibria will still have sorting of high-signal workers into promotion-promise entry-level positions. The complementarity between the two policies remains.

\section{Data}

The data come from the Worker Employment Relations Survey (WERS) 2004, a matched employer-employee data set from the United Kingdom. The survey was conducted by the Department of Trade and Industry, the Economic and Social Research Council, the Advisory, Conciliation and Arbitration Service, and the Policy Studies Institute. It is the fifth such survey in this series, which aims to study conditions in the workplace throughout Great

\footnotetext{
${ }^{30}$ The exception would be when the worker gets an abnormally large share of the surplus, in which case it maybe optimal for committed firms to "sell" supervisory jobs to low-signal workers.
} 


\section{Britain.}

The survey of each establishment took place in four parts. First, the Management Questionnaire (MQ) was administered in a roughly two-hour face-to-face interview with a management representative. The Employee Representative Questionnaire (ERQ) was conducted in person with both a union and non-union employee representative, when available. This interview typically lasted 45 minutes. The Supplemental Employee Questionnaire (SEQ) was distributed to a random sample of 25 employees at the establishment to gather basic information on the establishment's employees. This questionnaire was self-administered. In establishments with fewer than 25 employees, all of the establishment's employees were surveyed. Finally, a Financial Questionnaire (FQ) was completed by the establishment's financial manager on the establishment's recent financial performance. For this paper, data from the MQ and SEQ are linked to form a sample of employees matched with characteristics of their employing establishments, as reported by management.

One shortcoming of the SEQ is that many of the variables are categorical. This is particularly problematic for the wage and income data. The survey asks the workers for their weekly income, hourly wage, and number of hours they work per week. Workers are given the choice of 14 weekly income categories, but only 4 wage categories. The wage categories are also very unbalanced. The third highest (second lowest) category is for hourly wages between $£ 4.50-£ 5.00$, while the second highest category has a range of $£ 5.00-£ 15.00$.

I impute hourly wages by dividing the midpoint of the weekly income categories by the continuously measured weekly hours variable. For the unbounded category, which is weekly income of $£ 871$ or more, I use the value 950 . I include an indicator in any regression that involves wages for whether the wage was imputed from a top-coded income. ${ }^{31}$ This requires that the measurement error due to the categorical transformation is orthogonal to the estimated value, so that the mean is roughly equal to the midpoint of each category, and that hours worked is orthogonal to any deviations in income from the midpoint. While the

\footnotetext{
${ }^{31}$ In practice, this affects only $6.5 \%$ of my final weighted sample, and less than $1.5 \%$ of my final weighted sample of "entry-level" workers.
} 
assumption is strong, it is commonly made. ${ }^{32}$

The data consist of 22,451 workers surveyed from 2,295 unique establishments. Included in these data are 4-digit occupation and industry codes, as well as a variety of questions in the MQ that are linked to the specific 1-digit occupation codes within that establishment. In order to focus on establishment practices, rather than the results of collective bargaining, I drop all union members from the data set. ${ }^{33}$ I also eliminate all workers who work less than 30 hours per week or whose imputed wages are less than $£ 1 /$ hour. I drop all workers who do not have a valid response for ethnicity, gender, age, education, occupation, and supervisor status, and anyone employed at an establishment that does not have a valid industry code. After modifying my sample in this way, I am left with 9,348 unique workers from 1,533 different establishments.

I take my promotion policy measure from the MQ. The question asks "Which of these statements best describes your approach to filling vacancies at this workplace?" Managers then chose whether internal candidates or external candidates were given preferences for vacancies, or whether both types of candidates were given equal opportunity. Roughly $93 \%$ of the establishments weighted by employment in the survey reported that they either gave preference to internal candidates or gave no preference to either type. Throughout the paper I will refer to establishments that report favoring internal candidates as "internally focused", which I equate to the promotion-promise firms in my model. This same question was previously used by DeVaro and Morita (2013) to ascertain an establishment's promotion practices.

The model's predictions are focused only on a subset of the jobs that are observed at a firm: entry-level and supervisory positions. I classify "entry-level" jobs as non-managerial

\footnotetext{
${ }^{32}$ As a robustness check, I used ordered probits with the cut points constrained to match the actual $(\log )$ income categorical cutoffs in the survey. I exploit the fact that $\ln$ (Wage) $=\ln$ (Weekly Income) $-\ln ($ Hours), by controlling for the log of hours worked and constraining the coefficient on this variable to be equal to one. Thus all coefficients are identified and are marginal wage effects. This requires an alternative, but equally strong assumption that errors in wage are distributed log-normally. This approach yields similar results, though my tests have less power than the midpoint approach. These results are available upon request.

${ }^{33} \mathrm{I}$ do this as it is the finest definition of union membership that I have, and therefore will allow me to keep the most observations. Using alternative definitions of union influence, as well as including all union members in my regressions, does not meaningfully affect the results.
} 
and non-supervisory jobs, while managers and supervisors correspond to my model's supervisory job. ${ }^{34}$ In Table 1, I present summary statistics for each sub-sample using the weights provided by the survey makers for the SEQ. Education in the survey is given in terms of certificates earned through the UK schooling system. In the table, I reduce the seven categories given in the survey to five, though I use all seven as controls in regressions that use worker characteristics. ${ }^{35}$ While worker characteristics are somewhat different between internally-focused and externally-focused establishments, the distribution of occupations is quite similar. In both sub-samples, workers at internally-focused establishments are more educated and earn higher wages. I can reject the equality of the distribution of education using a Kolmogorov-Smirnov test. The differences in worker occupations appears to be small. The biggest differences are among professionals, skilled trades, and personal service, which encompasses occupations such as nurses, hairdressers, and travel agents. Workers at internally-focused establishments are more likely to be classified as professionals while being less likely to be in the latter two, particularly at the entry-level.

While there is no way to directly test in the survey for whether firms who report favoring internal candidates actually practice more frequent internal promotion, the observed distribution of tenure in Table 1 supports this notion. Supervisors are more likely to have less than one year of tenure with the establishment at externally-focused establishments than internally-focused establishments, indicating they are employing a higher fraction of external hires. ${ }^{36}$ Although the distribution of tenure among internally-focused supervisors as a

\footnotetext{
${ }^{34}$ This is slightly different from DeVaro and Morita (2013). They classify professionals as high level jobs, and do not have access to information on supervisors, since it is only available at the worker level. My classification is more appropriate in this setting, since it is unlikely that one would be promoted into the position of lawyer, while one could be promoted from a lawyer to a managing partner. Reclassifying professionals as supervisory jobs yields similar results.

${ }^{35}$ Workers were asked to check each of the categories of education certifications they possessed. The seven categories are: no academic qualifications, GCSE grades D-G and equivalents, GCSE grades A-C and equivalents, 1 GCE 'A' level grades A-E or 1-2 SCE Higher grades A-C or AS levels, 2 or more GCE 'A' levels A-E or 3 or more SCE Higher grades A-C, First Degree, and Higher (Postgraduate) Degree. Respondents were also given the option to choose "other academic certification." I do not use that category since it is indeterminate whether that certification is higher or lower than the others chosen by the respondent.

${ }^{36}$ This difference is statistically significant at the $5 \%$ level. Additionally, by combining the lowest two tenure bins we can see that managers and supervisors at externally-focused establishments are also more likely to have less than two years of tenure at the establishment. This latter difference is significant at the $10 \%$ level.
} 
whole does not stochastically dominate that of externally-focused supervisors, this is not necessarily implied by an internal promotion strategy. There could be other reasons outside the model that supervisors at establishments that do not favor internal promotion may have more supervisors with very high levels of tenure. ${ }^{37}$

Table 2 shows descriptive statistics at the establishment level, using weights designed to be representative of the average worker's place of employment. ${ }^{38}$ Consistent with previous studies (DeVaro and Morita, 2013), internally-focused establishments are larger and appear to be part of firms which employ more people in the United Kingdom. This latter difference is not statistically significant. There is no difference in the age of the establishment across promotion types, suggesting that the decision to promote is not related to being part of a newer, more innovative establishment. The percentage of the establishment's employees who are trade union members and the yearly turnover are also identical across both promotion types. Internally-focused establishments are much more likely to offer incentive pay to at least some employees. The table lists the distribution for the largest non-managerial 1-digit occupation code at the establishment. While these statistics vary between the internallyfocused and externally-focused establishments, there is no single type of occupation that is unrepresented in one of the promotion strategies. The lowest representation is for the Personal Service category in internally-focused establishments, which makes up $4 \%$ of that type.

\footnotetext{
${ }^{37}$ For instance, if firms that favor internal promotion successfully recruit higher quality supervisors, they may have more market opportunities outside the firm later in their careers. Additionally, recent work by Ke, $\mathrm{Li}$, and Powell (2014) shows that the optimal behavior of a firm which practices strict internal promotion may also include forced attrition policies at the management level to increase promotion opportunities for young workers.

${ }^{38}$ The alternative set of establishment weights, which are designed for analysis of the average establishment, weight small workplaces much more highly due to their prevalence in spite of the low fraction of employment they represent.
} 


\section{Testing the Model Empirically}

\subsection{Main Results}

I first test whether entry-level job workers at internally-focused establishments earn higher wages initially and have a lower observed return to tenure. ${ }^{39}$ I estimate the following equation

$$
\ln \text { Wage }_{i}=\beta_{0}+\beta_{1} X_{i}+\beta_{2} * \text { Promotion }_{i}+\beta_{3} * \text { Tenure }_{i}+\beta_{4} * \operatorname{Promotion}_{i} * \text { Tenure }_{i}+\epsilon_{i}
$$

where $X_{i}$ is a vector of controls and promotion is an indicator for whether the establishment prefers internal promotion. ${ }^{40}$ My model predicts that $\beta_{2}>0$ and $\beta_{4}<0$. I transform the tenure categories into a continuous variable using the midpoints of the bins, and include a dummy variable for those who are in the top bin. ${ }^{41}$ I use my sample of entry-level job workers, which consists of non-managerial and non-supervisory workers.

Table 3 shows the results of this regression. The first column contains only the promotion dummy, tenure, and the tenure interaction with no additional controls. The coefficients on both promotion and the interaction match up with the prediction and are jointly significant at the $1 \%$ level. Non-managerial, non-supervisory workers at establishments that prefer promotion earn on average $14 \%$ more than those at establishments that do not, conditional on tenure. The relevant comparison for the model, however, is for workers at identical jobs. Therefore, column 2 controls for 3-digit occupation code from the UK Standard Occupation Classification 2000 system (SOC2000) and 3-digit industry code from the UK Standard Industry 2003 system (SIC2003). Consistent with the predictions, the premium paid by

\footnotetext{
${ }^{39}$ While there has been a substantial literature interested in estimating the causal returns to tenure (e.g. Altonji and Williams, 2005), my model's predictions do not refer to differences in the causal return to tenure. They are instead wage differences based on changes in the equilibrium occupational sorting patterns within a worker's life-cycle in the firm. While estimating differences in the causal return to tenure may be of additional interest, conventional methods of estimating such require panel data on worker wages which are not available in the WERS 2004. See Altonji and Shakotko (1987) and Topel (1991).

${ }^{40}$ In order to ease the comparison across promotion policies, I do not allow tenure to enter the wage regression non-linearly as is standard in the literature. Results using non-linear specifications are generally consistent with the model.

${ }^{41}$ The results are robust to using both the upper or lower bounds of the bin, alternatively, to define tenure. Specifications using the tenure categories are also generally supportive of the model.
} 
internally-focused establishments is $6 \%$, but these non-managerial, non-supervisory workers have a 0.8 percentage point lower observed return to tenure. ${ }^{42}$ Both coefficients are statistically significant. The return to tenure at internally-focused establishments is only slightly more than half that at externally-focused establishments. ${ }^{43}$

In column 3, I replace the industry and occupation codes with controls for education, ethnicity, gender, and age. ${ }^{44}$ Both coefficients of interest have the right sign and are significant. Column 4 adds the industry and occupation codes back into the regression with the worker controls. The worker controls do not substantially alter the results when compared to the regression with just the industry and occupation codes, though the tenure interaction is now somewhat stronger. Given that my predictions are on equilibrium sorting patterns and these controls are observable correlates of ability, we would expect these controls to reduce the magnitude of the coefficients on both promotion and the interaction. This is indeed the case for the promotion coefficient. Comparing column 3 to column 1 and column 4 to column 2, the observed effect of being at an internally-focused firm is smaller, and significantly so in the former case at the $10 \%$ level. The coefficient on the interaction moves in the wrong direction when comparing column 1 to column 3, though this change is not statistically significant. There is virtually no change in the interaction term when comparing 2 to 4 .

Finally, in column 5, I add controls for the region of the establishment and the log number of its employees. ${ }^{45}$ The establishment-size wage premium has been well documented and, as seen in the descriptive statistics, establishments that focus internally are larger on average

\footnotetext{
${ }^{42}$ The return to tenure at both internally-focused and externally-focused establishments is lower than typical ordinary least squares estimates (Altonji and Williams, 2005). This is likely due to the sample selection excluding supervisors, who have both longer tenure and higher wages.

${ }^{43}$ It is likely that there are things outside the model that would cause differences in the return to tenure at the industry and occupation level. The results are robust to interacting tenure with both sets of codes. The model is also robust to controlling for the top-heaviness of the hierarchy through the fraction of workers who are employed as managers at the establishment. This was previously noted as a difference between establishments with different promotion practices by DeVaro and Morita (2013).

${ }^{44}$ The education controls include 6 dummies to represent, from lowest to highest achievement: No academic qualifications, GCSE grade D-G equivalent, GCSE grade A-C equivalent, 1 GCE A-level equivalent, 2 or more GCE A-level equivalents, Bachelor's degree equivalent, and graduate degree. The ethnicity controls are 16 dummies that represent British, Irish, other white, white and Black Caribbean, white and Black African, white and Asian, other mixed, Indian, Pakistani, Bangladeshi, other (South) Asian, Caribbean, African, other Black, Chinese, other ethnic group, and those who coded multiple of these.

${ }^{45}$ The results are robust to using levels instead of logs.
} 
than those that do not. One concern is that the promotion variable is simply proxying for establishment size. Though establishment size does appear to have a positive impact on wages, adding this control has little effect on the coefficients of interest. Alternatively using firm size in the UK, as well as interacting tenure with establishment size does not affect the results.

My model makes a specific prediction about the wages of the most senior entry-level job workers. The higher wages at internally-focused firms are due to the higher expected future value they will bring the firm upon promotion. The market, however, learns about the ability of old workers. Since talent is scarce, any old worker who remains in an entry-level job at any type of firm must be unqualified. Further, old workers die at the end of the period; even if they were qualified their impending mortality precludes any future value to the firm. Thus, the wages paid to workers at entry-level jobs should be identical at both types of firms.

In Table 4, I test this using the samples of non-managerial, non-supervisory workers with the most seniority. Column 1 and 2 use the highest tenure bin, which is ten years or higher. Controlling for industry and occupation, there is no statistically significant difference in wages across promotion policies for this tenure group. The results are virtually unchanged when controlling for worker characteristics, and establishment size and location. ${ }^{46}$ Given that this tenure bin is unbounded above, there is some concern that there may be large differences in tenure within this category that are masking a true difference in the correlation between wages and promotion policies. This is less of a concern when using the second highest tenure bin, which is bounded between five and ten years. In columns 3 and 4, I show that there is similarly no statistically significant difference in wages across promotion policies for this group.

\footnotetext{
${ }^{46}$ I note that the reduced sample size increases the standard error of the estimate, thus making it harder to find significance. However, even if I were to obtain estimates with the same precision as the comparable main results in table 5 (i.e column 2 and column 5 for Table 4's column 1 and 2, respectively), a standard $t$-test would still fail to reject at the $10 \%$ level.
} 


\subsection{Sorting and Productivity Differences}

Much of the predicted wage differences between workers at internally- and externally-focused establishments are due to sorting. If one could observe the signal received by the market, the entry-level jobs at internally-focused establishments would be primarily populated by workers with the high signal, while those jobs at externally-focused establishments would be primarily populated by workers with the low signal. Workers at supervisory jobs in internally-focused establishments would also primarily have the high signal, since they are chosen only from the population of entry-level workers at such establishments. However, the supervisory jobs at externally-focused establishments would also be populated by highsignal workers hired away from internally-focused establishments, meaning we would expect the degree of sorting to be less. Unfortunately, there is no such question in the survey. Instead, I use ordered logits to look for sorting on education, an observable characteristic that is correlated with higher levels of productivity and presumably a better market signal.

The first column of Table 5 looks at all workers controlling only for the employer's promotion policy. Workers at internally-focused establishments are significantly more likely to have higher levels of education than those at externally-focused establishments. This is true even when controlling for industry, occupation, geography and other worker characteristics. The third and fourth columns break the sorting down by job type. While both supervisory and entry-level job workers are more likely to have higher levels of education at internallyfocused establishments, this effect is only statistically significant for the latter. To test the hypothesis that there is more sorting on education in entry-level jobs than supervisory jobs, I estimate an ordered logit that fully nests both job types. Though not statistically significant, the interaction between entry-level job status and working at an internally-focused establishment is positive, which is consistent with the theory.

One major concern is that promotion could be proxying for establishment-level productivity differences. The WERS FQ offers three different measures of establishment level productivity: profits, value added, and the capital/labor ratio. Capital/labor ratio and prof- 
itability, in particular, have been shown to be positive correlates of the wage, at least at the industry level (Dickens and Katz, 1986). Unfortunately, the response rate to the FQ was much lower than other parts of the survey; less than half of the participating companies returned a FQ. This severely reduces the sample size. Only 1,791 of my non-managerial non-supervisory workers work at an establishment with a valid entry for capital/labor ratio.

Table 6 shows the results of adding these controls to the log wage regressions of nonmanagerial, non-supervisory workers. ${ }^{47}$ The results provide further support for the model. ${ }^{48}$ Though the coefficient on promotion is insignificant when controlling only for value added, it is estimated with less precision due to the smaller sample size, and is not statistically significantly different from the estimate in column 5 of Table 3 . The interaction between being at an internally-focused establishment and tenure is always significant and is larger, though not significantly so, than estimates seen without these controls previously. Given that each of these three measures is a noisy measure of the firm's productivity, the best specification would be to control for all three simultaneously. ${ }^{49}$ Under this specification in column (4) both coefficients of interest are large and statistically significant.

\footnotetext{
${ }^{47}$ There are a few theoretical problems with adding firm productivity measures to a wage regression. In a competitive market, wages are equal to marginal product. If the production function is Cobb-Douglas, $\log$ wage is a linear function of just the log of the capital/labor ratio. Value added (revenue - variable cost) divided by labor is just a linear transformation of the capital/labor ratio, as is profits less fixed costs divided by worker. In this setting, this type of regression would simply be of wage on wage. My model's setting is slightly different, in that young workers at entry-level jobs earn wages above their marginal product in equilibrium, but this rent disappears for old workers and it is still unclear what further controls in the regression could account for. Despite these concerns, this is a regression which is frequently estimated, and can still provide some insight into the robustness of my main results.

Another possible concern is that these productivity differences are outcomes of firm hiring policy, rather than firm characteristics. Any difference in the productivity measures I use, however, would have to come from factors outside my model. Each firm in equilibrium earns equal profits (0) and employs the same amount of capital (one factory). Firms do vary in size in my model, but since I control for log establishment size and because ratios are linear in logs, these differences will not confound my results.

${ }^{48}$ Table 6 reports results using logs of these productivity controls. Roughly $25 \%$ of the sample of nonmanagerial, non-supervisory workers whose establishment reported their profits were employed by an establishment that had negative profits. A smaller portion of workers also worked for a firm who reported negative value added. To avoid dropping these workers and thus creating a selected sample, I re-code all profits per full time worker and value added per full time worker that were less than 1 to be equal to 1 , and include a dummy variable indicating whether a worker's establishment had been re-coded in such a way in each specification where that variable was included. The results are robust to instead adding a constant to the variable before taking logs so as to make all values positive, or to simply using the levels of the productivity measures.

${ }^{49} \mathrm{I}$ am indebted to Michael Waldman for pointing this out.
} 


\subsection{Cross-Industry Differences}

As I discussed in the theory section, it is difficult to get definite predictions on cross-industry differences because there can be both differences in the composition of the equilibrium for different parameterizations and multiple equilibria for the same set of parameters. However, if we restrict attention to just full-sorting equilibria, there are two clear predictions: industries in which there are more high-signal workers will have more establishments who make promotion promises, and industries in which there are more frictions (as measured by the cost of search plus the difference in expected productivity of externally and internally-focused firm supervisors) will have higher entry-level promotion wages. Of course any assumptions on what constitutes a high-signal and what constitutes frictions will be necessarily ad hoc. Still, it is interesting to see if the metrics at the industry-level look reasonable.

Table 7 shows the fraction of establishments in each industry, using the main sections of the SIC2003, who prefer to promote internally. ${ }^{50}$ The industries with the highest fraction of internally-focused establishments, finance and manufacturing, seem quite logical. In both industries there are many observable characteristics that could differentiate high- from low-potential young employees. In the finance industry this could come in the form of elite graduate and undergraduate degrees. In manufacturing it can come in the form of certifications and apprenticeships. The lower end of the spectrum includes education, personal service, and hotels and restaurants which are unlikely to have such observable predictors. ${ }^{51}$

In Table 8, I estimate the entry-level internal-focus premium and the interaction between promotion and tenure separately for each industry. The estimates are all fairly imprecise given the severely reduced sample sizes, however the point estimates can still be of interest. In spite of being the industry with the largest fraction of establishments favoring promotion,

\footnotetext{
${ }^{50}$ These estimates use the employment weights provided by the WERS discussed previously.

${ }^{51}$ For example, the large productivity gains among teachers associated with small early gains in experience likely represent the discovery and sorting out of teachers who possess unobservably poor skills. These gains can be as large if not larger than that for formal training (Clotfelter, Ladd, and Vigdor, 2007).

It may be surprising that health and social work, which includes the medical professions, also has a low promotion rate, but this industry is likely organized in a somewhat unique way, due to the medical residency system, etc.
} 
there is no entry-level internal-focus premium paid at finance establishments. This likely reflects the competitiveness of the industry's labor market; when there are few frictions the benefit to avoiding them, which is passed back to entry-level workers through higher wages, is small. Instead, the largest internal-focus premium appears in wholesale and retail trade. This could, for instance, be due to specialization in the knowledge of products making it costly to identify outside alternatives.

Table 8 presents two interesting tests of the full-sorting equilibrium. First, in industries that pay higher internal-focus premiums to entry-level workers, there should be larger negative interaction between promotion policy and tenure. This is necessary to ensure that all experienced entry-level workers are paid the same. Second, if the surplus sharing at the supervisory-level is fairly equitable, in industries with a large entry-level internal-focus premium, internally-focused establishments should also be observed as paying higher wages to supervisors. This is because the internal-focus premium represents the extra potential profits from the promotion-promise strategy to the firm. If they are large, it is likely they are large because the establishment is able to employ better quality supervisors than those that look externally, which should be reflected in their salaries. I estimate these wages for managers and supervisors in column 3. The results are supportive in both cases. The correlation between columns (1) and (2) of Table 8 is strongly negative, while the correlation between column (1) and (3) is positive.

While I caution placing too much weight on the strength of the results of the crossindustry regressions, they do largely support the model, and in particular the full-sorting equilibrium. There is no evidence here to suggest the underlying story is incorrect.

\subsection{Alternative Explanations}

Given that my theory is meant to be complementary to existing theories of promotion, it is important to analyze whether it is necessary. In this section I consider whether one could obtain identical predictions from a more conventional model of promotion. In each case I find that an additional component that induces sorting would be required. 
Starting with the most classic model, my results may seem somewhat consistent with a Lazear-Rosen (1981) tournament story. In a typical tournament as incentives model, those who do not get promoted receive lower wages as a punishment to induce higher effort in the initial period. The first dilemma is how to classify the different promotion practices. If we suppose the firms that prefer to promote internally are practicing a tournament and those that do not are not using promotions to incentivize workers, then the lower return to tenure from promotion "losers" is consistent with trying to offer a prize-spread to induce effort. Problematically for this story, Table 4 shows that the most senior non-promoted workers are paid identical wages across promotion practices. Thus, working in a promotion tournament is a dominant strategy. One can earn a higher initial wage, exert zero effort, and be paid the same as those who did not enter the tournament. Both types of practices cannot exist in this scenario without a sorting mechanism..$^{52}$

Alternatively, we could suppose that both types of policies represent a tournament but each policy is organized differently. As shown by Chan $(1996,2003)$, when firms can engage in external recruitment the increased competition reduces the incentives for workers to engage in high effort; they have a lower chance of winning the tournament for every effort level. The firm has two options: either give preference to internal candidates or increase the prize of the tournament through a larger spread between the winners and losers. To investigate whether firms that do not give preferences to internal candidates offer a higher spread, I estimate the differences in wages for managers and supervisors by firm promotion policy in Table 9. If anything this evidence suggests that firms that prefer to promote internally pay higher wages to their supervisors. ${ }^{53}$ Given that the most senior entry-level workers are paid identical wages across different promotion policies, there is no evidence of a larger spread, and thus this tournament approach alone seems insufficient. ${ }^{54}$

\footnotetext{
${ }^{52}$ This could perhaps be rectified if the promotion tournament firms fired workers who shirked. Ignoring whether this would be optimal, while I cannot observe firing rates by occupation in the data, there is no evidence that firings, layoffs, or turnover overall is higher among establishments which prefer internal promotion.

${ }^{53}$ Note that in the first columns I do not control for tenure, since workers with identical tenure are not directly comparable; externally-focused firms will be hiring supervisors more often from outside the firm.

${ }^{54}$ One may worry that this approach is confounded by the fact that I cannot observe separately who
} 
The promotions as signals approach could provide an explanation for the higher initial wages paid at firms that prefer to promote internally. As originally noted by Bernhardt (1995), when promotion acts as a signal of high ability to the market, non-promotion must also act as a signal of low ability. If a firm's favorable promotion practice reveals more negative information on low ability workers to the market than one that does not frequently promote internally, the premium could account for risk-aversion on the part of workers who are more likely to face this negative shock. However, the fact that long-tenured entry-level workers appear to be paid equally across promotion strategy types is inconsistent with this approach. Another mechanism is again necessary. ${ }^{55}$

One might also think that firms may favor internal promotion because they require specific human capital for their operation. ${ }^{56}$ If workers at promotion-promise firms obtain specific human capital and those at no-promise firms invest in general human capital, the former will have a lower observed return to tenure than the latter since the market only rewards general human capital. Thus, promotion-promise firms would have to offer higher wages in order to attract workers. However, for this model to work, it would have to be that the no-promise workers are eventually paid more, so that the lifetime expected wages are the same. This is again contradicted by the results of Tables 4 and 9, which show that longterm employees of promotion-promise establishments do not earn less than similar workers at no-promise establishments at any task.

was promoted internally and that firms offer different salaries to external and internal hires. However, the interaction between tenure and promotion shows that even among the most senior employees, whose longevity with the firm suggests they were promoted internally, supervisors are not paid more at firms which do not give preference to internal candidates. Further the weight of empirical evidence from other studies suggests that external hires are paid more than internal hires, which would suggests that the Table 9 understates the positive gap in wages between firms that give preference to internal candidates and those that do not. See Murphy and Zábojník (2007), Bidwell (2011), and Kampkötter and Sliwka (2014). Hassink and Russo (2008) also find that external hires earn more than the average worker at a firm, but less than workers who recently changed jobs within a firm.

${ }^{55}$ One additional way to address the issue of incentives is to look at the interaction between incentive pay and promotion policy. While there are conflicting ideas as to whether tournaments and monetary incentives are complements or substitutes (e.g. Kwon, 2006 and Frederiksen and Takats, 2011), I observe that my predicted wage patterns hold regardless of whether the establishment offers incentive pay.

${ }^{56}$ For an example of the importance of specific human capital and promotion, see Murphy and Zábojník (2004, 2007). They show that one can explain recent increases in the compensation to, and reduction in internal promotion of, CEOs with a decrease in the relative importance of specific versus general human capital. 


\section{Summary and Conclusion}

In this paper, I developed a new model of promotions in equilibrium, which explains heterogeneity in promotion practices across firms. Ex ante identical firms promise to eventually promote one of their workers to a more valuable task before workers are hired, and thus avoid the costs of hiring from a frictional labor market. These firms must then be more selective in their entry-level hiring. In addition to being good entry-level workers, they must also be good candidates for supervisory tasks. The viability of such a strategy is limited by the number of such workers in the labor force. An internal promotion strategy always requires better skilled candidates than one that looks externally.

My model predicts that workers at entry-level jobs at firms that favor internal promotion should have higher wages, but lower observed returns to tenure. Promotion-promise firms are willing to pay a premium for entry-level workers who are likely to become good supervisors since their future profits are more directly tied to the skills of their entry-level employees. Once the uncertainty has been resolved, this premium disappears. There are no differences in the wages of the most senior workers in jobs that differ only in their firm's promotion policy. I confirm these predictions in the data. Also consistent with my model is sorting on observables, where educated workers are more likely to be employed at internally-focused establishments than externally-focused establishments. These results cannot be explained by the conventional promotions as incentives or specific human capital models alone and are not driven by differences in establishment-level productivity.

The results suggest the further study of other complementary strategies. Given that internally-focused firms require a highly qualified workforce at the entry-levels, it would be of interest to understand how their recruitment strategies differ from those that look externally. Also, given that their lower ranked workforce is more skilled, a firm that prefers to promote internally may also use different production technologies, such as span of control or diversity in assigned tasks. This is certainly an avenue for future research.

My model also provides a potential explanation for inequality outcomes. Workers at 
promotion-promise firms, who have good observables in equilibrium, have a higher chance of earning a supervisory job even when they are revealed to not be of high ability. Applying this to the statistical discrimination literature, if blacks have poorer characteristics than whites that are observable to employers but not to the econometrician then, even conditional on other observables and ability, blacks may perform poorer than whites in the long run. This is consistent with evidence presented by Altonji and Pierret (2001).

Overall, while incentives may play an important role in the labor market within a firm, incentivizing workers to enter the firm is important when looking between firms that do and do not promote. Emphasizing internal promotion cannot be successful without selective hiring at the lower ranks. The quality of the labor pool is thus a constraint on the number of firms who can profitably implement an internal labor market. 


\section{References}

Altonji, Joseph G. and Charles R. Pierret. 2001. "Employer Learning and Statistical Discrimination." The Quarterly Journal of Economics 116 (1): 313-350.

Altonji, Joseph G. and Robert A. Shakotko. 1987. "Do Wages Rise With Job Seniority?" The Review of Economic Studies 54 (3): 437-459.

Altonji, Joseph G. and Nicolas Williams. 2005. "Do Wages Rise with Job Seniority? A Reassessment." Industrial and Labor Relations Review 58 (3): 370-397.

Bayo-Moriones, Alberto and Pedro Ortin-Angel. 2006. "Internal Promotion versus External Recruitment in Industrial Plants in Spain." Industrial and Labor Relations Review 59 (3): 451-470.

Bernhardt, Dan. 1995. "Strategic Promotion and Compensation." The Review of Economic Studies 62 (2): 315-339.

Bidwell, Matthew. 2011. "Paying More to Get Less: The Effects of External Hiring versus Internal Mobility." Administrative Science Quarterly 56 (3): 369-407.

Brynjolfsson, Erik and Paul Milgrom. 2013. "Complementarity in Organizations." in The Handbook of Organizational Economics, eds. Robert Gibbons and John Roberts. Princeton University Press: Princeton, NJ.

Chan, William. 1996. "External Recruitment versus Internal Promotion." Journal of Labor Economics 14 (4): 555-570.

Chan, William. 2006. "External Recruitment and Intrafirm Mobility." Economic Inquiry 44 (1): 169-184.

Chen, Kong-Pin. 2005. "External Recruitment as an Incentive Device." Journal of Labor Economics 23 (2): 259-277.

Clotfelter, Charles T., Helen F. Ladd, and Jacob L. Vigdor. 2007. "How and Why do Teacher Credentials Matter for Student Achievement?" NBER Working Paper No. 12828.

DeVaro, Jed and Hodaka Morita. 2013. "Internal Promotion and External Recruitment: A Theoretical and Empirical Analysis." Journal of Labor Economics 31 (2): 227-270.

DeVaro, Jed and Michael Waldman. 2012. "The Signaling Role of Promotions: Further Theory and Evidence." Journal of Labor Economics 30 (1): 91-147.

Dickens, William T. and Lawrence F. Katz. 1986. "Interindustry Wage Differences and Industry Characteristics." NBER Working Paper No. 2014.

Frederiksen, Anders, and Elod Takats. 2011. "Promotions, Dismissals, and Employee Selection: Theory and Evidence." The Journal of Law, Economics, and Organization 27 (1): 159-179.

Ghosh, Suman. 2007. "Job mobility and careers in firms." Labour Economics 14 (3): 603-621. 
Ghosh, Suman and Michael Waldman. 2010. "Standard promotion practices versus up or out contracts." The RAND Journal of Economics 41 (2): 301-325.

Gibbons, Robert and Michael Waldman. 1999. "A Theory of Wage and Promotion Dynamics Inside Firms." The Quarterly Journal of Economics 114 (4): 1321-1358.

Gibbons, Robert and Michael Waldman. 2006. "Enriching a Theory of Wage and Promotion Dynamics Inside Firms." Journal of Labor Economics 24 (1): 59-107.

Hassink, Wolter and Giovanni Russo. 2008. "Wage differences between internal and external candidates." International Journal of Manpower 29 (8): 715-730.

Ke, Rongzhu, Jin Li, and Michael Powell. 2014. "Managing Careers in Organizations." unpublished.

Kampkötter, Patrick and Dirk Sliwka. 2014. "Wage Premia for Newly Hired Employees: Theory and Evidence." Labour Economics. 31: 45-60.

Kräkel, Matthias and Schöttner, Anja. 2012. "Internal Labor Markets and Worker Rents." Journal of Economic Behavior and Organization 84 (2): 491-509.

Kwon, Illoong. 2006. "Incentives, wages, and promotions: theory and evidence." The RAND Journal of Economics 37 (1): 100-120.

Lazear, Edward P. and Paul Oyer. 2013. "Personnel Economics." in The Handbook of Organizational Economics, eds. Robert Gibbons and John Roberts. Princeton University Press: Princeton, NJ..

Lazear, Edward P. and Sherwin Rosen. 1981. "Rank-Order Tournaments as Optimum Labor Contracts." The Journal of Political Economy 89 (5): 841-864.

Li, Hao and Sherwin Rosen. 1998. "Unraveling in Matching Markets." The American Economic Review 88 (3): 371-387.

Martins, Pedro and Francisco Lima. 2006. "External Recruitments and Firm Performance." Applied Economics Letters 13 (14): 911-915.

Murphy, Kevin J. and Ján Zábojník. 2004. "CEO Pay and Appointments: A Market-Based Explanation for Recent Trends." The American Economic Review 94 (2): 192-196.

Murphy, Kevin J. and Ján Zábojník. 2007. "Managerial Capital and the Market for CEOs." Unpublished manuscript, University of Southern California.

Oyer, Paul and Scott Schaefer. 2011. "Personnel Economics: Hiring and Incentives." in Handbook of Labor Economics, eds. Ashenfelter, Orley and David Card. Elsevier: Amsterdam.

Topel, Robert H. 1991. "Specific Capital, Mobility, and Wages: Wages Rise with Job Seniority." Journal of Political Economy 99 (1): 145-176.

Tsoulouhas, Theofanis, Charles R. Knoeber and Anup Agrawal. 2007. "Contests to become CEO: incentives, selection and handicaps." Economic Theory 30 (2): 195-221. 
Waldman, Michael. 1984. "Job Assignments, Signaling, and Efficiency." The Rand Journal of Economics 15 (2): 255-267.

Waldman, Michael. 2003. "Ex Ante Versus Ex Post Optimal Promotion Rules: the Case of Internal Promotion." Economic Inquiry 41 (1): 27-41.

Waldman, Michael. 2007. "Theory and evidence in internal labor markets." MPRA Paper No. 5113

Waldman, Michael. 2013. "Classic Promotion Tournaments versus Market Based Tournaments." International Journal of Industrial Organization 31 (3): 198-210.

Department of Trade and Industry. Employment Markets Analysis and Research et al. , Workplace Employee Relations Survey, 2004: Cross-Section Survey, 2004 and Panel Survey, 1998-2004; Wave 2 [computer file]. 4th Edition. Colchester, Essex: UK Data Archive [distributor], January 2008. SN: 5294.

Zábojník, Ján. 2012. "Promotion tournaments in market equilibrium." Economic Theory 51 (1): 213-240.

Zábojník, Ján and Dan Bernhardt. 2001. "Corporate Tournaments, Human Capital Acquisition, and the Firm-Size Wage Relation." Review of Economic Studies 68 (3): 693-716. 


\section{A Proofs of Main Results}

\section{A.1 Proof of Lemma 5}

Proof. First note that since unpromoted old workers are viewed as identical by the market, they must earn an identical wage. All old workers at entry-level positions produce $\theta$ regardless of type, so both incumbent and non-incumbent firms are only willing to offer $\theta$ to old workers for entry-level positions. Since there are always more old workers than there are supervisory positions, the wage for unknown type old workers hired for supervisory positions will be $\theta$ as well.

\section{A.2 Proof of Proposition 6}

Proof. From Lemma 5, we know that a firm can hire an external worker with an unknown type at wage $\theta$. If there were any external workers that were qualified, then promotionpromise firms with two unqualified internal candidates would fulfill their promise only if they could pay their internal workers less than $\theta$ to work as a supervisor. However, no internal worker would accept such a wage as they could earn $\theta$ on the market. They are both not known to be unqualified by other firms and able to produce $\theta$ at the entry-level position. In other words, the surplus from employing the unqualified worker as a supervisor is negative. Thus some promotion-promise firms would break their promise when talent is not scarce, so any equilibrium without talent scarcity must be trivial.

\section{A.3 Proof of Proposition 7}

Proof. From Proposition 6, we know that in non-trivial equilibria, talent is always scarce, so all old workers who are not employed as supervisors after the search market clears are unqualified. Since firms always choose to promote internal unqualified workers when indifferent between hiring internally and externally, any firm which does not hire a qualified supervisor from the search market will promote internally. Thus, if a firm did not promise promotion and did not enter the search market, we would be in violation of Self-Enforcing Contracts.

\section{A.4 Proof of Proposition 8}

Proof. First note that workers are indifferent between promotion practices, since they do not impact their utility so long as talent is scarce. Because unqualified supervisors are always in excess supply, they do not extract a surplus from working at a supervisory job if they are promoted when unqualified. When talent is scarce all qualified workers obtain a supervisory job regardless of their initial firm's policy. Workers thus take their highest wage offer, and the law of one price holds for labor.

Workers always generate positive product so there is no unemployment. Because $h<\frac{1}{2}$, there must always be some firm which employs two low-signal workers at the entry-level position. Denoting $\phi$ as the probability of finding a qualified worker when conducting a search, the profits for this firm if they do not promise to promote are

$$
\pi_{L L}^{n p}=2 \theta+\left[1-\left(1-p_{L}\right)^{2}(1-\phi)\right] \psi \lambda \theta-r-m-2 w_{L}
$$

The first part of this expression is the productivity of the workers at the entry-level. The second is the probability of obtaining a qualified supervisor multiplied by the firm's share of 
the surplus from doing so given this policy and employment composition. The final terms are the costs of capital, search and labor. The profits for a firm that makes a promotion promise are

$$
\pi_{L L}^{p}=2 \theta+\left[1-\left(1-p_{L}\right)^{2}\right] \psi \lambda \theta-r-2 w_{L}
$$

Given $r$, for the factory market to have cleared, it must be that no firms earn positive profits. So, we can determine wages by setting the profit functions equal to zero. Taking the difference between these two wages, we find that the promotion-promise contract will outbid the no promise contract, and thus this strategy can exist in equilibrium if and only if

$$
m>\phi\left(1-p_{L}\right)^{2} \psi \lambda \theta
$$

In words, a firm will adopt a promotion promise when employing two low-signal workers only when the cost of search exceeds the benefit.

Now consider firms who employ high-signal workers. If they employ two high-signal workers the profits for the no-promise firm will be

$$
\pi_{H H}^{n p}=2 \theta+\left[1-\left(1-p_{H}\right)^{2}(1-\phi)\right] \psi \lambda \theta-r-m-2 w_{H}
$$

while for the promotion-promise firm is

$$
\pi_{H H}^{p}=2 \theta+\left[1-\left(1-p_{L}\right)^{2}(1-\phi)\right] \psi \lambda \theta-r-2 w_{H}
$$

and thus, the promotion-promise firm will outbid the no-promise firm when

$$
m>\phi\left(1-p_{H}\right)^{2} \psi \lambda \theta
$$

Finally for the contract that employs both low and high-signal workers at entry level,

$$
\pi_{H L}^{n p}=2 \theta+\left[1-\left(1-p_{H}\right)\left(1-p_{L}\right)(1-\phi)\right] \psi \lambda \theta-r-m-w_{H}-w_{L}
$$

and similarly for promotion-promise contracts,

$$
\pi_{H L}^{p}=2 \theta+\left[1-\left(1-p_{H}\right)\left(1-p_{L}\right)\right] \psi \lambda \theta-r-w_{H}-w_{L}
$$

and thus, the promotion-promise contract will outbid the no-promise contract so long as

$$
m>\phi\left(1-p_{H}\right)\left(1-p_{L}\right) \psi \lambda \theta
$$

Now, because $p_{H}>p_{L}$ note that

$$
\phi\left(1-p_{H}\right)^{2} \psi \lambda \theta<\phi\left(1-p_{H}\right)\left(1-p_{L}\right) \psi \lambda \theta<\phi\left(1-p_{L}\right)^{2} \psi \lambda \theta
$$

Thus for a given equilibrium $\phi$, if $m$ is high enough that firms strictly prefer to promise to promote with two low-signal workers, they will also prefer to do so when employing highsignal workers, and the equilibrium is trivial - there is no set of firms conducting an external search that has positive measure. Likewise, if $m$ is low enough that firms would not promise to promote if they employed two high-signal workers, they would also not promise when employing any low-signal worker. Thus there is no set of firms that has positive measure 
and contains firms that promise to promote. Only intermediate values of $m$ will result in a non-trivial equilibrium and in these values it must be the case that the high-signal worker contracts will have a promotion promise while the low-signal worker contracts will not, given the ordering of these inequalities. Thus there will always be sorting of high-signal workers into promotion promise contracts.

\section{A.5 Proof of Proposition 10}

Proof. In this proof, I show one set of parameters under which both promotion policies co-exist, but there are an infinite number of other sets with this property.

First, I will set

$$
m=\phi\left(1-p_{H}\right)\left(1-p_{L}\right) \psi \lambda \theta
$$

which, from the proof of Proposition 8 will imply that firms that hire two low-signal entrylevel workers will never prefer to offer a promise, firms that hire two high-signal entry-level workers will always prefer to offer a promise, and firms that hire one of each signal-type will be indifferent between the promotion regimes (see section A.4).

We know from factory market clearing that

$$
r=\phi \psi \lambda \theta-m
$$

which is the revenue from entering the market and purchasing a factory, but not hiring any young entry-level workers. Given this, the profits for the no-promise firms in this equilibrium are

$$
\pi_{L L}^{n p}=2 \theta+\left[\left(1-\left(1-p_{L}\right)^{2}\right](1-\phi) \psi \lambda \theta-2 w_{L}\right.
$$

and so the equilibrium wage for the low-signal workers will be

$$
w_{L}=\theta+\frac{1}{2}\left[\left(1-\left(1-p_{L}\right)^{2}\right](1-\phi) \psi \lambda \theta\right.
$$

Firms that hire two high-signal workers promise to promote internally, and their profits are

$$
\pi_{H H}^{p}=2 \theta+\left[\left(1-\left(1-p_{H}\right)^{2}-\left(1-\left(1-p_{H}\right)\left(1-p_{L}\right)\right) \phi\right] \psi \lambda \theta-2 w_{H}\right.
$$

and thus the high-signal wage will be

$$
w_{H}=\theta+\frac{1}{2}\left[\left(1-\left(1-p_{H}\right)^{2}-\left(1-\left(1-p_{H}\right)\left(1-p_{L}\right)\right) \phi\right] \psi \lambda \theta\right.
$$

Since at the level of $m$ I have chosen, firms are indifferent between promising and not promising to promote when employing both signal-types of workers at any wage level, it suffices to check only one of these cases. The profits from promoting with one high- and one low-signal worker would be

$$
\pi_{H L}^{p}=2 \theta+\left[1-\left(1-p_{H}\right)\left(1-p_{L}\right)\right] \psi \lambda \theta-r-w_{H}-w_{L}
$$

Substituting for the equilibrium wages,

$$
\pi_{H L}^{p}=\frac{1}{2}\left(p_{H}-p_{L}\right)^{2} \psi \lambda \theta-\frac{1}{2} \phi\left(1-p_{L}\right)\left(p_{H}-p_{L}\right) \psi \lambda \theta
$$


This is negative, and thus Contract Optimality is satisfied if

$$
\left(1-p_{L}\right) \phi>\left(p_{H}-p_{L}\right)
$$

Note that $\phi$ is simply the number of qualified workers who are not promoted internally divided by the number of supervisor vacancies at firms that enter the search market. The latter is just the number of no-promise firms where both entry-level workers were revealed as unqualified. Given that all $h$ high-signal workers are employed on promise contracts and all $(1-h)$ low-signal workers are employed on no-promise contracts, for $N \approx 2$

$$
\phi=\frac{\frac{1}{2} h p_{H}^{2}+\frac{1}{2}(1-h) p_{L}^{2}}{(1-h)\left(1-p_{L}\right)^{2}}
$$

It is easy to find parameters for which $\phi<1$, which allows for talent scarcity and SelfEnforcing Contracts, and $\left(1-p_{L}\right) \phi>\left(p_{H}-p_{L}\right)$. For example, $p_{H}=.6, p_{L}=.3$, and $h=.49$.

\section{A.6 Proof of Corollary 11}

Proof. Proposition 10 proves the existence of a steady-state, non-trivial equilibrium.

\section{A.7 Proof of Proposition 12}

Proof. From Proposition 8 we know that the the average signal-type of workers is higher at promotion-promise firms than no-promise firms. Since wages do not vary with firm policy (see A.4) and high-signal workers are paid more than low, average wages must be higher at promotion-promise firms.

\section{A.8 Proof of Proposition 13}

Proof. This proposition is directly implied by Lemma 5. 
Table 1: Descriptive Statistics - Workers

\begin{tabular}{|c|c|c|c|c|}
\hline & \multicolumn{2}{|c|}{ Entry-Level } & \multicolumn{2}{|c|}{ Supervisory } \\
\hline & $(\overline{1)}$ & $(2)$ & $(3)$ & $(4)$ \\
\hline & Internal & External & Internal & External \\
\hline \multicolumn{5}{|l|}{ Tenure } \\
\hline \multirow[t]{2}{*}{$<1$ year } & 0.26 & 0.27 & 0.11 & 0.13 \\
\hline & $(0.44)$ & $(0.45)$ & $(0.31)$ & $(0.34)$ \\
\hline \multirow[t]{2}{*}{$1-2$ years } & 0.16 & 0.17 & 0.12 & 0.13 \\
\hline & $(0.37)$ & $(0.38)$ & $(0.33)$ & $(0.33)$ \\
\hline \multirow[t]{2}{*}{$2-5$ years } & 0.29 & 0.28 & 0.33 & 0.28 \\
\hline & $(0.45)$ & $(0.45)$ & $(0.47)$ & $(0.45)$ \\
\hline \multirow{2}{*}{$5-10$ years } & 0.17 & 0.14 & 0.21 & 0.21 \\
\hline & $(0.38)$ & $(0.35)$ & $(0.41)$ & $(0.41)$ \\
\hline \multirow{2}{*}{$>10$ years } & 0.12 & 0.13 & 0.23 & 0.25 \\
\hline & $(0.32)$ & $(0.34)$ & $(0.42)$ & $(0.43)$ \\
\hline \multicolumn{5}{|l|}{ Education } \\
\hline None & 0.18 & 0.23 & 0.08 & 0.14 \\
\hline GSCE & 0.36 & 0.40 & 0.34 & 0.35 \\
\hline GCE & 0.17 & 0.13 & 0.16 & 0.16 \\
\hline First Degree (BSc, BA, etc.) & 0.24 & 0.18 & 0.32 & 0.28 \\
\hline Higher Degree (MSc, PhD, etc.) & 0.06 & 0.05 & 0.11 & 0.08 \\
\hline \multirow{2}{*}{ Wage (Imputed) } & 8.76 & 7.75 & 12.76 & 11.27 \\
\hline & $(3.99)$ & $(3.54)$ & $(5.28)$ & $(5.15)$ \\
\hline \multicolumn{5}{|l|}{ Occupation (1-digit SOC2000) } \\
\hline Professionals & 0.13 & 0.09 & 0.10 & 0.11 \\
\hline Technical Operations & 0.19 & 0.16 & 0.12 & 0.13 \\
\hline Administrative & 0.24 & 0.22 & 0.12 & 0.12 \\
\hline Skilled Trades & 0.07 & 0.11 & 0.04 & 0.08 \\
\hline Personal Service & 0.03 & 0.07 & 0.02 & 0.04 \\
\hline Sales & 0.11 & 0.09 & 0.05 & 0.05 \\
\hline Process and Machine Operatives & 0.13 & 0.12 & 0.05 & 0.03 \\
\hline Elementary Occupation & 0.10 & 0.13 & 0.05 & 0.05 \\
\hline Managers & & & 0.44 & 0.39 \\
\hline Observations & 1798 & 3591 & 1334 & 2625 \\
\hline
\end{tabular}

Source: WERS 2004 SEQ. Means and standard deviations are reported using weights provided with data. 
Table 2: Descriptive Statistics - Employers

\begin{tabular}{lccc}
\hline & $(1)$ & $(2)$ & $(3)$ \\
& All & Internal & External \\
\hline Vacancy Policy & 0.00 & 0.01 & 0.00 \\
Internal Only & $(0.06)$ & $(0.12)$ & $(0.00)$ \\
& 0.28 & 0.99 & 0.00 \\
Internal Preferred & $(0.45)$ & $(0.12)$ & $(0.00)$ \\
& 0.66 & 0.00 & 0.93 \\
No Preference & $(0.47)$ & $(0.00)$ & $(0.26)$ \\
& 0.01 & 0.00 & 0.01 \\
External Preferred & $0.09)$ & $(0.00)$ & $(0.10)$ \\
& 0.04 & 0.00 & 0.06 \\
External Only & $(0.20)$ & $(0.00)$ & $(0.24)$ \\
& 477.16 & 595.55 & 429.83 \\
Employees at Establishment & $(1157.40)$ & $(1432.05)$ & $(1024.27)$ \\
& 8902.53 & 10465.74 & 8257.95 \\
Employees in UK & $(17430.74)$ & $(18358.91)$ & $(17000.89)$ \\
& 41.21 & 41.28 & 41.19 \\
Establishment Age & $(60.69)$ & $(55.48)$ & $(62.68)$ \\
Percent Union Members & 0.25 & 0.25 & 0.25 \\
& $(0.31)$ & $(0.31)$ & $(0.31)$ \\
Prior Year Turnover & 0.21 & 0.21 & 0.21 \\
& $(0.20)$ & $(0.20)$ & $(0.20)$ \\
Offers Incentive Pay & 0.48 & 0.61 & 0.42 \\
Largest Occupation (1-digit SOC2000) & $(0.50)$ & $(0.49)$ & $(0.49)$ \\
Professionals & & & \\
Technical Operations & 0.13 & 0.10 & 0.14 \\
Administrative & 0.14 & 0.09 & 0.15 \\
Skilled Trades & 0.14 & 0.19 & 0.12 \\
Personal Service & 0.07 & 0.08 & 0.07 \\
Sales & 0.09 & 0.04 & 0.11 \\
Process and Machine Operatives & 0.15 & 0.19 & 0.14 \\
Elementary Occupation & 0.14 & 0.17 & 0.13 \\
Observations & 0.14 & 0.14 & 0.14 \\
\hline \hline Sol wers & 1533 & 422 & 1111 \\
\hline
\end{tabular}

Source: WERS 2004 MQ. Means and standard deviations are reported using employment weights provided with data 
Table 3: Non-Managerial, Non-Supervisory Workers - Internal-Focus Premium and Return to Tenure

$\begin{array}{lllll}(1) & (2) & (3) & (4) & (5)\end{array}$

Log Wage Log Wage Log Wage Log Wage Log Wage

\begin{tabular}{lccccc}
\hline Promotion & $0.136^{* * *}$ & $0.060^{* * *}$ & $0.102^{* * *}$ & $0.052^{* * *}$ & $0.041^{* *}$ \\
& $(0.032)$ & $(0.021)$ & $(0.024)$ & $(0.019)$ & $(0.018)$ \\
Tenure & $0.021^{* * *}$ & $0.020^{* * *}$ & $0.018^{* * *}$ & $0.013^{* * *}$ & $0.012^{* * *}$ \\
& $(0.004)$ & $(0.003)$ & $(0.003)$ & $(0.003)$ & $(0.003)$ \\
Promotion * Tenure & -0.010 & $-0.008^{*}$ & $-0.012^{* *}$ & $-0.009^{* *}$ & $-0.008^{* *}$ \\
& $(0.006)$ & $(0.004)$ & $(0.005)$ & $(0.004)$ & $(0.004)$ \\
Log Establishment Size & & & & & $0.021^{* * *}$ \\
& & & & & $(0.004)$ \\
Worker Characteristics & No & No & Yes & Yes & Yes \\
Occupation FE & No & Yes & No & Yes & Yes \\
Industry FE & No & Yes & No & Yes & Yes \\
Geographic FE & No & No & No & No & Yes \\
\hline Observations & 5389 & 5389 & 5389 & 5389 & 5389 \\
$F$-statistic & $9.911^{* * *}$ & $4.044^{* *}$ & $9.020^{* * *}$ & $3.931^{* *}$ & $2.936^{*}$ \\
\hline \hline
\end{tabular}

Robust standard errors are clustered at the establishment level. $F$-statistic tests joint hypothesis of promotion dummy and tenure interaction. Worker characteristics include 6 education dummies, 16 ethnicity dummies, 8 age dummies, and a gender dummy. Occupation fixed effects use the UK Standard Occupation Classification 2000 (SOC2000) 3-digit system. Industry fixed effects use the UK Standard Industry Classification 2003 (SIC2003) 3-digit system. Geographic fixed effects are indicators for Government Office Region. Indicators are included for all top-coded variables, including an interaction between the tenure top-code and the promotion dummy

${ }^{*} \mathrm{p}<.1, * * \mathrm{p}<.05, * * * \mathrm{p}<.01$ 
Table 4: Log Wage Regressions for Non-Managerial, Non-Supervisory Workers with High Seniority

\begin{tabular}{|c|c|c|c|c|}
\hline & (1) & $(2)$ & $(3)$ & $(4)$ \\
\hline & \multicolumn{2}{|c|}{$10+$ Years Tenure } & \multicolumn{2}{|c|}{ 5-10 Years Tenure } \\
\hline & Log Wage & Log Wage & Log Wage & Log Wage \\
\hline \multirow[t]{2}{*}{ Promotion } & $0.030^{* *}$ & 0.027 & 0.012 & 0.029 \\
\hline & $(0.037)$ & $(0.039)$ & $(0.030)$ & $(0.026)$ \\
\hline \multirow[t]{2}{*}{ Log Establishment Size } & & $0.025 * *$ & & 0.015 \\
\hline & & $(0.011)$ & & $(0.010)$ \\
\hline Worker Characteristics & No & Yes & No & Yes \\
\hline Occupation FE & Yes & Yes & Yes & Yes \\
\hline Industry FE & Yes & Yes & Yes & Yes \\
\hline Geographic FE & No & Yes & No & Yes \\
\hline Observations & 691 & 691 & 866 & 866 \\
\hline
\end{tabular}

Robust standard errors are clustered at the establishment level. Sample for column 1 and

2 are non-managerial non-supervisory workers with greater than 10 years of tenure.

Sample for columns 3 and 4 are non-managerial, non-supervisory workers with between five and ten years of tenure. Worker characteristics include 6 education dummies, 16 ethnicity dummies, 8 age dummies and a gender dummy. Occupation fixed effects use the UK Standard Occupation Classification 2000 (SOC2000) 3-digit system. Industry fixed effects use the UK Standard Industry Classification 2003 (SIC2003) system. Geographic fixed effects are indicators for Government Office Region. Indicators are included for all top-coded variables.

$* \mathrm{p}<.1,{ }^{* *} \mathrm{p}<.05, * * * \mathrm{p}<.01$

Table 5: Ordered Logit Regressions on Highest Educational Attainment

\begin{tabular}{lcccc}
\hline & $(1)$ & $(2)$ & $(3)$ & $(4)$ \\
& All Workers & All Workers & Entry-Level & Supervisory \\
\hline Promotion & $0.338^{* * *}$ & $0.120^{*}$ & $0.151^{*}$ & 0.070 \\
& $(0.095)$ & $(0.063)$ & $(0.082)$ & $(0.092)$ \\
Log Establishment Size & & $0.120^{* * *}$ & $0.081^{* * *}$ & $0.179^{* * *}$ \\
& & $(0.023)$ & $(0.028)$ & $(0.034)$ \\
Worker Characteristics & No & Yes & Yes & Yes \\
Occupation FE & No & Yes & No & Yes \\
Industry FE & No & Yes & Yes & Yes \\
Geographic FE & No & Yes & Yes & Yes \\
\hline Observations & 9348 & 9348 & 5389 & 3959 \\
\hline \hline
\end{tabular}

Robust standard errors are clustered at the establishment level. Worker characteristics include 16 ethnicity dummies, 8 age dummies, and a gender dummy. Occupation fixed effects use the UK Standard Occupation Classification 2000 (SOC2000) 3-digit system. Industry fixed effects use the UK Standard Industry Classification 2003 (SIC2003) 3-digit system. Geographic fixed effects are indicators for Government Office Region. Indicators are included for all top-coded variables.

${ }^{*} \mathrm{p}<.1,{ }^{* *} \mathrm{p}<.05,{ }^{* * *} \mathrm{p}<.01$ 
Table 6: Non-Managerial Non-Supervisory Workers - Establishment Productivity Measures

(1) (2) (3)

\begin{tabular}{lcccc} 
& Log Wage & Log Wage & Log Wage & Log Wage \\
\hline Promotion & $0.061^{*}$ & 0.033 & $0.060^{*}$ & $0.061^{*}$ \\
& $(0.031)$ & $(0.029)$ & $(0.032)$ & $(0.034)$ \\
Tenure & $0.014^{* * *}$ & $0.014^{* * *}$ & $0.015^{* * *}$ & $0.017^{* * *}$ \\
& $(0.004)$ & $(0.004)$ & $(0.005)$ & $(0.006)$ \\
Promotion * Tenure & $-0.013^{* *}$ & $-0.013^{* *}$ & $-0.015^{* *}$ & $-0.016^{* * *}$ \\
& $(0.005)$ & $(0.005)$ & $(0.006)$ & $(0.006)$ \\
Log Establishment Size & $0.024^{* * *}$ & $0.032^{* * *}$ & $0.021^{* * *}$ & $0.027^{* * *}$ \\
& $(0.007)$ & $(0.006)$ & $(0.010)$ & $(0.007)$ \\
Log Profits / Worker & 0.010 & & & 0.022 \\
& $(0.009)$ & & & $(0.016)$ \\
Log Value Added / Worker & & $0.016^{*}$ & & 0.003 \\
& & $(0.009)$ & & $(0.023)$ \\
Log Capital / Worker & & & $0.020^{* *}$ & $0.021^{* *}$ \\
Worker Characteristics & & & $(0.010)$ & $(0.010)$ \\
Occupation FE & Yes & Yes & Yes & Yes \\
Industry FE & Yes & Yes & Yes & Yes \\
Geographic FE & Yes & Yes & Yes & Yes \\
\hline Observations & 2206 & 2405 & 1791 & Yes \\
F-statistic & $2.967^{*}$ & $3.318^{* *}$ & $3.071^{* *}$ & $3.666^{* *}$ \\
\hline \hline
\end{tabular}

Robust standard errors are clustered at the establishment level. $F$-statistic tests joint hypothesis of promotion dummy and tenure interaction. Establishments with profits or value added per worker less than one were re-coded as 1 before taking logs. An indicator for whether an establishment was re-coded in such a way is included in all specifications with that variable. Worker characteristics include 6 education dummies, 16 ethnicity dummies, 8 age dummies, and a gender dummy. Occupation fixed effects use the UK Standard Occupation Classification 2000 (SOC2000)3-digit system. Industry fixed effects use the UK Standard Industry Classification 2003(SIC2003) 3-digit system. Indicators are included for all top-coded variables including an interaction between the tenure top-code and the promotion dummy.

${ }^{*} \mathrm{p}<.1,{ }^{* *} \mathrm{p}<.05, * * * \mathrm{p}<.01$ 
Table 7: Internally-Focused Establishments by Industry

\begin{tabular}{lcc}
\hline & $(1)$ & $(2)$ \\
& Sample & Internal \\
\hline Manufacturing & 0.15 & 0.43 \\
Electricity & 0.00 & 0.37 \\
Construction & 0.04 & 0.21 \\
Wholesale and Retail Trade & 0.16 & 0.32 \\
Hotels and Restaurants & 0.04 & 0.21 \\
Transport, Storage, and Communication & 0.07 & 0.38 \\
Finance & 0.05 & 0.55 \\
Real Estate and Rental & 0.15 & 0.31 \\
Public Administration & 0.06 & 0.24 \\
Education & 0.08 & 0.08 \\
Health and Social Work & 0.15 & 0.14 \\
Other Personal Service & 0.05 & 0.19 \\
\hline Observations & 1533 & 422 \\
\hline \hline
\end{tabular}

Source: WERS 2004 MQ. Industry estimates use employment weights provided with the data. 
Table 8: Internal-Focus Premium, Tenure Interaction, and Supervisory Wages by Industry

(1)

$(2)$

(3)

\begin{tabular}{|c|c|c|c|}
\hline & \multicolumn{2}{|c|}{ Entry-Level } & \multirow{2}{*}{$\frac{\text { Supervisory }}{\text { Promotion }}$} \\
\hline & Promotion & Promotion $*$ Tenure & \\
\hline \multirow[t]{2}{*}{ Manufacturing } & 0.012 & 0.001 & 0.016 \\
\hline & $(0.041)$ & $(0.007)$ & $(0.064)$ \\
\hline \multirow[t]{2}{*}{ Electricity } & 0.066 & 0.017 & 1.039 \\
\hline & $(0.464)$ & $(0.058)$ & $(1.087)$ \\
\hline \multirow[t]{2}{*}{ Construction } & 0.038 & -0.020 & $0.204^{* *}$ \\
\hline & $(0.084)$ & $(0.019)$ & $(0.102)$ \\
\hline \multirow[t]{2}{*}{ Wholesale and Retail Trade } & $0.198^{* * *}$ & $-0.022^{*}$ & -0.083 \\
\hline & $(0.059)$ & $(0.011)$ & $(0.085)$ \\
\hline \multirow[t]{2}{*}{ Hotels and Restaurants } & -0.046 & 0.014 & 0.124 \\
\hline & $(0.099)$ & $(0.025)$ & $(0.134)$ \\
\hline \multirow[t]{2}{*}{ Transport, Storage, and Communication } & 0.045 & -0.018 & 0.004 \\
\hline & $(0.080)$ & $(0.021)$ & $(0.116)$ \\
\hline \multirow[t]{2}{*}{ Finance } & -0.038 & 0.000 & -0.028 \\
\hline & $(0.073)$ & $(0.017)$ & $(0.089)$ \\
\hline \multirow[t]{2}{*}{ Real Estate and Rental } & 0.049 & -0.003 & $0.114^{* *}$ \\
\hline & $(0.051)$ & $(0.012)$ & $(0.053)$ \\
\hline \multirow[t]{2}{*}{ Public Administration } & -0.086 & 0.023 & -0.019 \\
\hline & $(0.061)$ & $(0.015)$ & $(0.133)$ \\
\hline \multirow[t]{2}{*}{ Education } & 0.153 & -0.028 & $0.494^{* *}$ \\
\hline & $(0.132)$ & $(0.047)$ & $(0.223)$ \\
\hline \multirow[t]{2}{*}{ Health and Social Work } & 0.008 & 0.009 & $-0.312^{* *}$ \\
\hline & $(0.086)$ & $(0.015)$ & $(0.133)$ \\
\hline \multirow[t]{2}{*}{ Other Personal Service } & 0.040 & -0.004 & 0.078 \\
\hline & $(0.068)$ & $(0.014)$ & $(0.185)$ \\
\hline Correlation with Column (1) & & -0.74 & 0.27 \\
\hline
\end{tabular}

Robust standard errors are clustered at the establishment level. Column 1 and 2 estimates the coefficient on promotion and the interaction between promotion for entry-level workers controlling for worker characteristics, log establishment size and geographic FE separately by industry. Column 3 estimates the coefficient on promotion for supervisory workers controlling for worker characteristics and geographic FE separately by by industry. Column 3 does not control for tenure. The left-hand side for all regressions is log wage.

${ }^{*} \mathrm{p}<.1,{ }^{* *} \mathrm{p}<.05,{ }^{* * *} \mathrm{p}<.01$ 
Table 9: Log Wage Regressions for Managerial and Supervisory Workers

\begin{tabular}{lccccc}
\hline & $(1)$ & $(2)$ & $(3)$ & $(4)$ & $(5)$ \\
& Log Wage & Log Wage & Log Wage & Log Wage & Log Wage \\
\hline Promotion & $0.074^{* * *}$ & 0.020 & 0.009 & 0.032 & 0.001 \\
& $(0.025)$ & $(0.018)$ & $(0.016)$ & $(0.031)$ & $(0.028)$ \\
Tenure & & & & $0.008^{* *}$ & $0.006^{* *}$ \\
& & & & $(0.003)$ & $(0.003)$ \\
Promotion * Tenure & & & & -0.002 & 0.004 \\
& & & $0.029^{* * *}$ & $(0.006)$ & $(0.005)$ \\
Log Establishment Size & & & $(0.005)$ & & $0.028^{* * *}$ \\
& No & No & Yes & No & $(0.005)$ \\
Worker Characteristics & No & Yes & Yes & Yes & Yes \\
Occupation FE & No & Yes & Yes & Yes & Yes \\
Industry FE & No & No & Yes & No & Yes \\
Geographic FE & 3959 & 3959 & 3959 & 3959 & 3959 \\
\hline Observations & & & & & \\
\hline \hline
\end{tabular}

Robust standard errors are clustered at the establishment level. Worker characteristics include 6 education dummies, 16 ethnicity dummies, 8 age dummies, and a gender dummy. Occupation fixed effects use the UK Standard Occupation Classification 2000 (SOC2000) 3-digit system. Industry fixed effects use the UK Standard Industry Classification 2003 (SIC2003) 3-digit system. Geographic fixed effects are indicators for Government Office Region. Indicators are included for all top-coded variables.

$* \mathrm{p}<.1, * * \mathrm{p}<.05, * * * \mathrm{p}<.01$ 